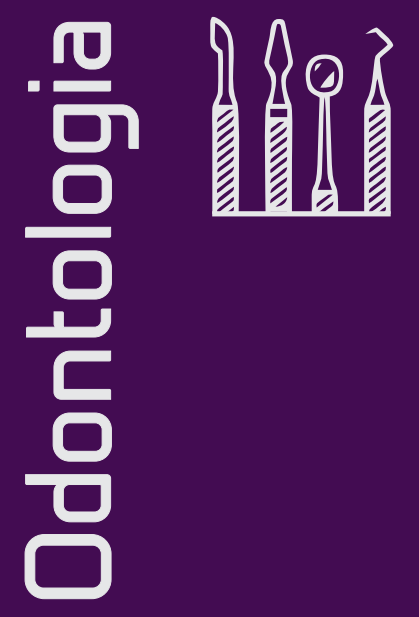

\title{
SISTEMAS ADESIVOS EM ODONTOLOGIA: DOS PRINCÍPIOS DE UNIÃO À TÉCNICA CLÍNICA
}

\section{Autores:}

Talita Arrais Daniel Mendes

Karlos Eduardo Rodrigues Lima

Vágner Herton Silva Diógenes Júnior

Carlos lury Sant'Ana Furtado

Gabriela Soares Santana 


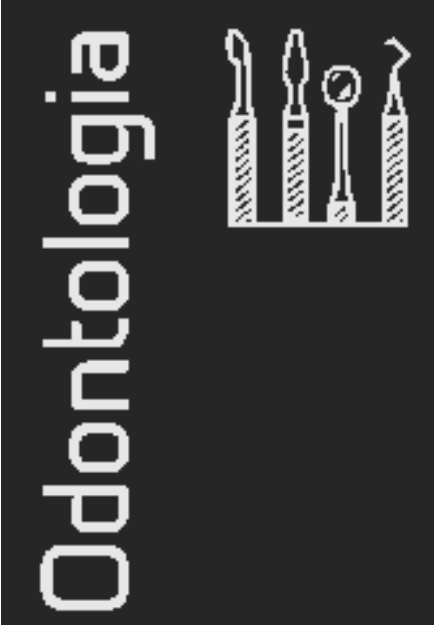

\section{SISTEMAS ADESIVOS EM ODONIOLOGIA: DOS PRINCÍPIOS DE UNIĀO À TÉCNICA CLÍNICA}

\section{Autores:}

Talita Arrais Daniel Mendes

Karlos Eduardo Rodrigues Lima

Vàgner Herton Silva Diógenes Júnior

Carlos lury Sant'Ana Furtado

Gabriela Soares Santana

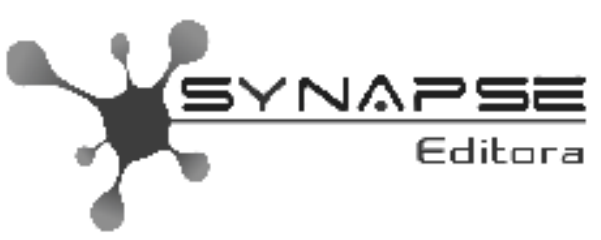

Compartilhando conhecimento 
Editor Chefe

Msc Washington Moreira Cavalcanti

Autores

Talita Arrais Daniel Mendes Karlos Eduardo Rodrigues Lima Vágner Herton Silva Diógenes Júnior Carlos lury Sant'Ana Furtado Gabriela Soares Santana

Conselho Editorial Msc Lais Brito Cangussu Msc Rômulo Maziero Msc Jorge dos Santos Mariano

Dr Jean Canestr

Msc Elias Rocha Gonçalves Júnior

Msc Daniela Aparecida de Faria

Projeto Gráfico e Diagramação Departamento de arte Synapse Editora

Edição de Arte Maria Aparecida Fernandes

Revisão Os Autores
2021 by Synapse Editora Copyright (C) Synapse Editora

Copyright do Texto (c) 2021 Os autores Copyright da Edição (c) 2021 Synapse Editora Direitos para esta edição cedidos à Synapse Editora pelos autores.

Todo o texto bem como seus elementos, metodologia, dados apurados e a correção são de inteira responsabilidade dos autores. Estes textos não representam de forma alusiva ou efetiva a posição oficial da Synapse Editora.

A Synapse Editora não se responsabiliza por eventuais mudanças ocorridas nos endereços convencionais ou eletrônicos citados nesta obra.

Os livros editados pela Synapse Editora, por serem de acesso livre, Open Access, é autorizado o download da obra, bem como o seu compartilhamento, respeitando que sejam referenciados os créditos autorais. Não é permitido que a obra seja alterada de nenhuma forma ou usada para fins comerciais.

O Conselho Editorial e pareceristas convidados analisaram previamente todos os manuscritos que foram submetidos à avaliação pelos autores, tendo sido aprovados para a publicação.

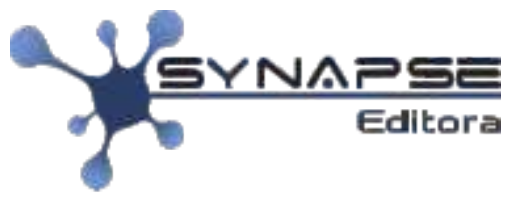

Compartillhando conhecimento 릴 
M538s Mendes, Talita Arrais Daniel

Sistemas adesivos em odontologia: dos princípios de união à técnica clínica Autores: Talita Arrais Daniel Mendes; Karlos Eduardo Rodrigues Lima; Vágner Herton Silva Diógenes Júnior; Carlos lury Sant'Ana Furtado; Gabriela Soares Santana.

Belo Horizonte, MG: Synapse Editora, 2021, 52 p.

Formato: PDF

Modo de acesso: World Wide Web.

Inclui bibliografia

ISBN: 978-65-88890-09-7

DOI: doi.org/10.36599/editpa-2021_saodpd

1. Odontologia, 2. Dentística restauradora, 3. Sistemas adesivos,

4. Técnica clínica, 6. Tratamento dentário.

I. Sistemas adesivos em odontologia: dos princípios de

SYNAPSE EDITORA

Belo Horizonte - Minas Gerais

CNPJ: 40.688.274/0001-30

Tel: + 5531 98264-1586

www.editorasynapse.org

editorasynapse@gmail.com

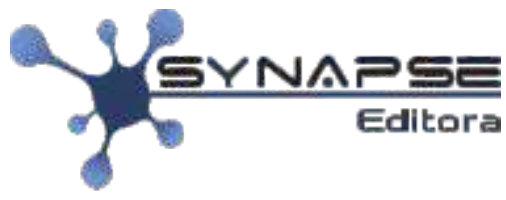

Compartillhando conhecimento

2021 


\section{Apresentação}

A odontologia adesiva embasa todo o contexto odontológico atual, tendo em vista que o processo adesivo engloba todas as áreas, desde a Dentística restauradora até a Ortodontia, por exemplo. Cabe ao Cirurgião-dentista saber empregar corretamente as técnicas adesivas de maneira correta para cada situação clínica específica, entretanto muitos acham um processo bastante complexo.

O presente livro demonstra com facilidade cada peculiaridade dos diversos tipos de sistemas adesivos, bem como as técnicas corretas para sua aplicabilidade em âmbito de clínica odontológica, visando dar segurança aos profissionais, para otimizar os procedimentos que possam lançar-se mão da técnica adesiva.

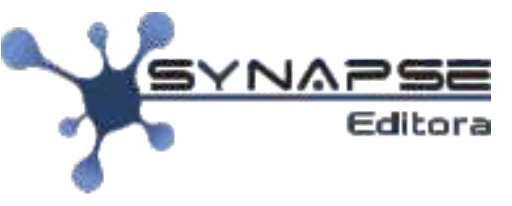

Compartillhando conhecimento 리기 

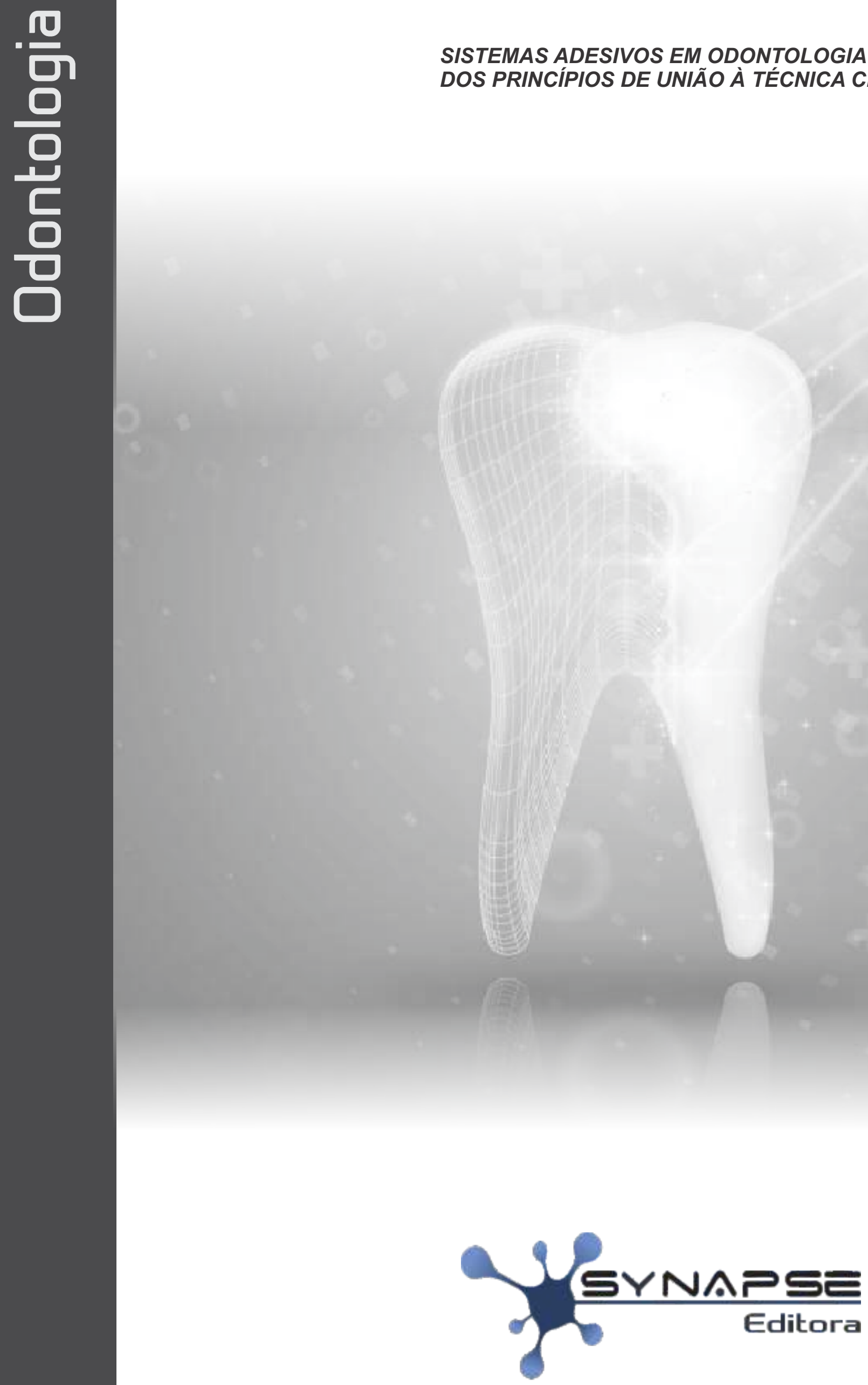

Compartilhando conhecimento

$$
\text { 리기 }
$$




\section{SISTEMAS ADESIVOS EM ODONTOLOGIA: \\ DOS PRINCÍPIOS DE UNIÃO À TÉCNICA CLÍNICA}

\section{Sumário}

CAPÍTULO 01:

PROPRIEDADES MECÂNICAS QUE INFLUENCIAM NO PROCESSO ADESIVO 8 CAPÍTULO 02:

SISTEMA ADESIVO DE CONDICIONAMENTO E LAVAGEM

CAPÍTULO 03:

ADESIVOS AUTOCONDICIONANTES

CAPÍTULO 04:

ADESIVOS UNIVERSAIS

CAPÍTULO 05:

MECANISMOS DE DEGRADAÇÃO DA INTERFACE DE UNIÃO

DENTINA/ADESIVO

CAPÍTULO 06:

BIOMATERIAIS DE PRESERVAÇÃO DA INTERFACE DE UNIÃO

CAPÍTULO 07:

TÉCNICAS ADESIVAS 


\section{Capitulo1}

\section{PROPRIEDADES MECÂNICAS \\ QUE INFLUENCIAM NO PROCESSO ADESIVO}

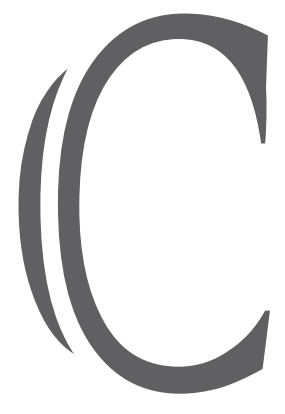

om a constante evolução no ramo da Ciência, bem como na Odontologia, percebeu-se que houve um aprimoramento dos materiais restauradores, mas para que haja uma boa empregabilidade desses materiais, precisa-se contar com um material que é responsável por criar uma união entre o substrato dental e a resina composta, a fim de que os tratamentos dentários se tornem conservadores e com uma boa longevidade nesta união ${ }^{1}$.

De priori, faz-se necessário diferenciar adesão de coesão, para que assim, se obtenha um bom entendimento dos mecanismos a serem abordados. A coesão é abordada como uma força intermoleculares exercidas em um mesmo material, no qual as tornam moléculas unidas. Já o entendimento sobre adesão, se trata da atração molecular de dois diferentes substratos. Além disso, para se formar uma boa adesão entre esses diferentes materiais, deve-se alcançar um íntimo contato entre as partes, sendo esse íntimo contato influenciado pela limpeza de ambas interfaces, havendo, 
dessa forma, um conjunto de mecanismos de origem física, química e mecânica que influenciam diretamente nesta união 2,3 .

Mecanismos de origem química ocorrem mediante a necessidade de haver uma proximidade, com isso, está relacionada quanto à superfície e a capacidade de molhamento do adesivo ao substrato dentário. E interações físicas depende das forças de valência secundárias, as mesmas ocorrem em dipolos moleculares, e na interação da nuvem de elétrons desprotegidos ${ }^{1}$.

Um dos princípios fundamentais da adesão está diretamente relacionado há um processo de troca de minerais existente entre os tecidos dentários e o material restaurador. Com isso, é feito a remoção desses minerais e o espaço é ocupado pela resina, ainda mais, cita-se que esse processo se constitui em duas fases, a que há uma remoção do cálcio e criação de micro retenções em esmalte e dentina, bem como na hibridização, onde há uma penetração e polimerização dos monômeros do interior das micro retenções criadas ${ }^{1}$.

Para que haja um íntimo contato entre o adesivo e o substrato dental, são necessários fatores essenciais, nos quais atuam para fornecer uma boa união micromecânica do sistema adesivo ao dente. São eles a propriedade de molhamento do adesivo, bem como a sua viscosidade e além da rugosidade superficial do substrato dentário ${ }^{4}$.

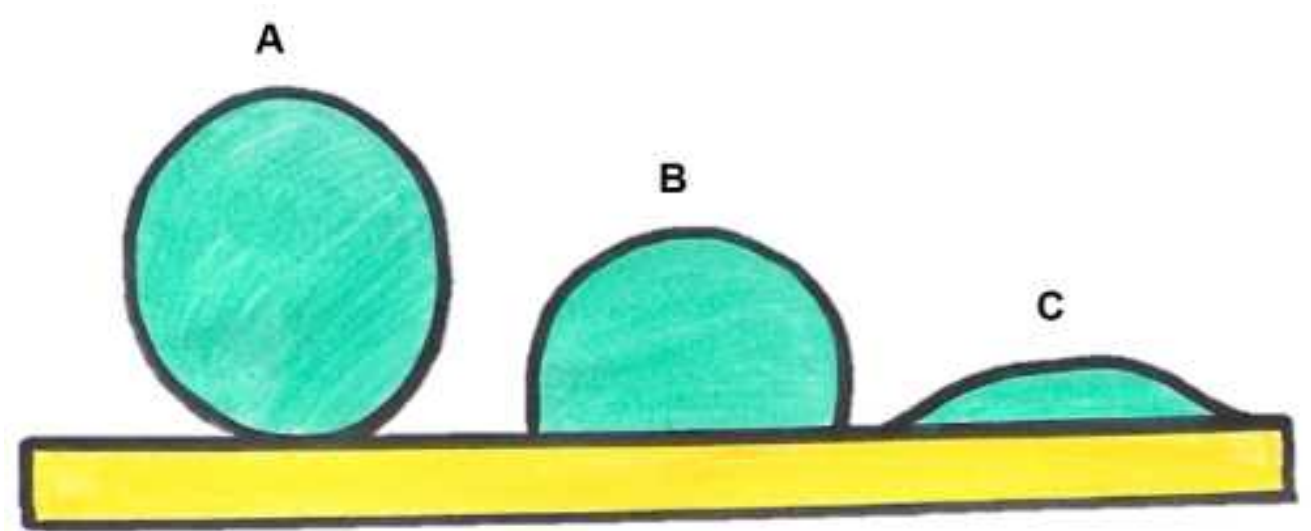

Figura 01: Capacidade de molhamento de um líquido, onde $A$ tem-se um líquido com menor molhamento que $B$ e $C$.

Fonte: Autores, 2021 
Desse modo, o molhamento se trata da capacidade de que um líquido (figura 01), no referido caso o adesivo, tem de se espalhar e recobrir toda a superfície do substrato ${ }^{4}$. 0 líquido apresenta a capacidade de escoar criando o íntimo contato com uma dada superfície, espalhando sobre as superfícies e penetrando nas irregularidades micro retentivas. Outro aspecto importante para a interação adesiva é a necessidade de contar com superfícies limpas, uma vez que a presença de contaminantes podem prejudicar a capacidade de molhamento do adesivo sobre o substrato ${ }^{3}$.

Um fator que pode influenciar no potencial de molhamento é o ângulo formado entre a superfície de um sólido e de um líquido colocados em contato ${ }^{4}$. Então, a melhor molhabilidade fornecida pelo líquido se dá por quanto menor é o ângulo de contato. Dessa forma, ângulos maiores de $90^{\circ}$ são considerados não compatíveis, maiores de $180^{\circ}$ já são considerados absolutamente não compatíveis, e o ideal, considera-se $0^{\circ}$, onde é absolutamente compatível ao processo adesivo (figura 02$)^{3}$.

Além disso, o molhamento pode ser melhorado também conforme se dá ao aumento da energia de superfície do substrato, onde quanto mais limpa essa superfície e quanto mais micro retenções existentes, obtém-se uma melhor energia de superfície ${ }^{3}$.

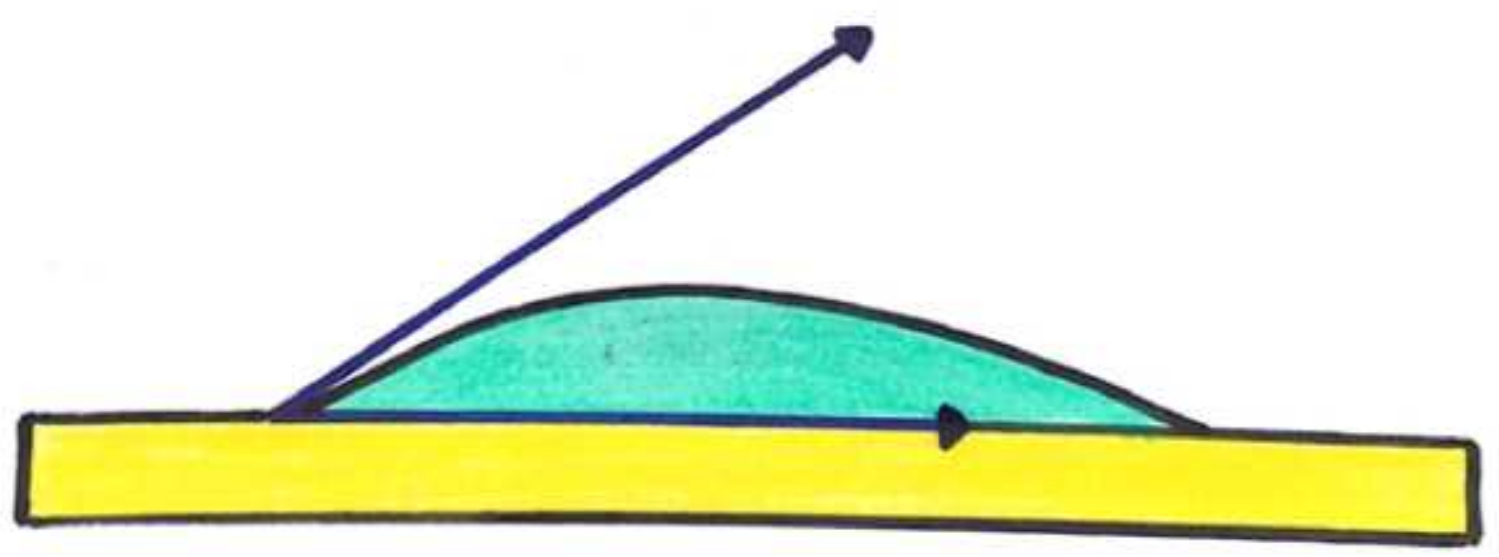

Figura 02: Ângulo de contato deve ser próximo a 0ํㅜ para melhor efetividade de união do adesivo.

Fonte: Autores, 2021 
A viscosidade também tem papel importante no processo de adesão. Pois, o ângulo de contato é diretamente proporcional a viscosidade do líquido. De maneira geral, o adesivo terá mais dificuldade em recobrir toda a superfície uma vez que sua consistência não for tão viscosa quanto ao essencial, bem como, também pode influenciar na criação de bolhas, e, assim, impedindo de adentrar nas micro retenções e impossibilitando essa boa adesão ${ }^{4}$. Um adesivo menos viscoso necessita de mais tempo para recobrir toda a superfície do substrato dental e apresentará, assim, mais facilidade no aprisionamento de ar, formando bolhas, com isso tornando-se prejudicial ao resultado que se busca quanto à molhabilidade e adesão ${ }^{5}$.

A rugosidade superficial, caracterizada por presença de micro retenções em uma superfície, também é um fator primordial que influencia nessa união entre o substrato dental e o material restaurador. Com isso, a mesma atua no aumento da área de contato, pois essa rugosidade permite que o adesivo adentre em mais sítios para retê-los ${ }^{4}$. Quanto maior a rugosidade do substrato, maior será o aumento de superfície e energia do substrato, e com isso, aumentará as regiões nos quais o adesivo adentrará nessas microporosidades, bem como, a aplicabilidade dos sistemas adesivos e adesão ${ }^{5}$.

Em suma, Colle (2017) finaliza discernindo que conseguir uma boa adesão e consequentemente ser conservadora e obter longevidade depende da presença de irregularidades e de impurezas, onde o substrato deve estar limpo de contaminantes e de uma boa energia livre de superfície do sólido bem como da tensão superficial do líquido. 


\section{REFERÊNCIAS}

1. Arinelli, A. M. D., Pereira, K. F., Prado, N. A. S., \& Rabello, T. B. (2016). Sistemas adesivos atuais. Revista Brasileira de Odontologia, 73(3), 242.

2. Colle, E. B. (2017). Princípios da Adesão Dental.

3. Anusavice, K. J., Shen, C., \& Rawls, H. R. (Eds.). (2012). Phillips' science of dental materials. Elsevier Health Sciences.

4. Reis, A., \& Loguercio, A. D. (2007). Materiais dentários diretos: dos fundamentos à aplicação clínica. Santos.

5. Hofstaetter, V. (2020). Sistemas adesivos autocondicionantes: uma revisão de literatura. 


\section{Capitulo2}

\section{SISTEMA ADESIVO DE CONDICIONAMENTO E LAVAGEM}

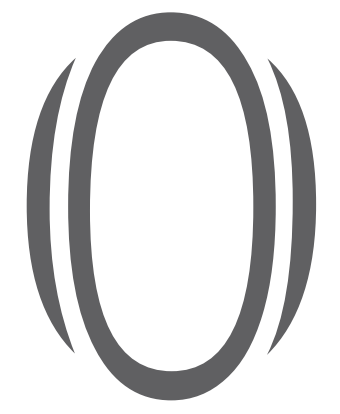

s sistemas adesivos são os responsáveis por estabelecerem a união entre os materiais restauradores e o substrato dental, sendo resultantes da associação de monômeros resinosos de divergentes pesos moleculares e viscosidades, diluentes resinosos e solventes, como a acetona, etanol e água ${ }^{1}$.

Os sistemas adesivos de condicionamento e lavagem ( $\mathrm{SACL}$ ), ou também denominados de convencionais, requerem um condicionamento ácido prévio da estrutura dental, sendo este condicionamento realizado, geralmente, com ácido fosfórico. Ele é responsável por remover a smear layer, ou também denominada de lama dentinária, que consiste em restos necróticos de dentina, bactérias, e outros remanescentes do preparo cavitário, sendo que esta camada pode ter uma espessura variando entre 1 a $5 \mu^{2}$. 


\section{COMPOSIÇÃO QUÍMICA}

O SACL é, então, composto, de modo geral, por ácido, primer e adesivo (Bond), sendo que o condicionamento ácido é com ácido fosfórico 3.

\section{Condicionamento ácido}

Apresenta como principal agente condicionante o ácido fosfórico, com concentrações variando entre 30 a 40\%, mas geralmente utiliza-se a concentração de $37 \%^{3}$. O tempo de aplicação vai depender do tipo de substrato que se está inserindo, em dentina deve-se limitar a 15 segundos e em esmalte, pode-se chegar até 30 segundos, seguido de uma lavagem abundante, pelo mesmo tempo de aplicação ${ }^{4}$.

Em esmalte tem-se uma desmineralização referente à $20 \mu \mathrm{m}$. Existem alguns fatores que dificultam o condicionamento em esmalte, como dentes decíduos, que possuem uma camada aprismática variando entre 2 a $3 \mu \mathrm{m}$, especialmente na região cervical, e pacientes mais idosos, uma vez que o dente torna-se menos permeável dificultando o condicionamento ${ }^{4}$.

Quando este condicionamento abrange o substrato dentinário, além de remover a smear layer, ocorre a eliminação de hidroxiapatita da zona mais superficial, cerca de 3 a $8 \mu \mathrm{m}$, o que reduz consideravelmente o teor de conteúdo mineral nas camadas subjacentes. Em virtude disso, o diâmetro dos túbulos dentinários é aumentado e a permeabilidade da dentina e a pressão intrapulpar também são elevadas, além de ocasionar a exposição de um tecido conjuntivo frouxo rico em fibras de colágeno, resultando numa estrutura menos mineralizada, mais úmida e porosa, o que pode comprometer o sucesso da técnica adesiva ${ }^{4}$. Já se sabe que esse material não causa dano significativo à polpa dentária ${ }^{4}$. 


\section{Primers}

Diante disso, utiliza-se os primers, que são soluções adesivas com caráter hidrofílico, que apresentam composições necessárias para manter a rede de colágeno expandida ao mesmo tempo em que o excesso de água é deslocado para permitir a infiltração dos monômeros hidrofílicos contidos no adesivo. Assim, os primers são compostos por monômeros hidrofílicos dissolvidos em solventes, tais como acetona, etanol ou água, apresentando ainda em sua composição o 2 - hidroxietil metacrilato (HEMA), sendo este importante em razão de suas características hidrofílicas devido a presença do seu grupamento hidroxila além de ter afinidade com monômeros hidrofóbicos devido à sua molécula conter também uma extremidade composta por metacrilato, além de apresentar características químicas próximas aos dos solventes. Desse modo, os solventes adicionados de monômeros hidrofílicos são carreados para dentro da dentina previamente desmineralizada e possibilitam a evaporação da água, deixando os monômeros hidrofílicos em contato com as fibrilas colágenas 3,4 .

\section{Adesivos}

Por fim, complementando o procedimento adesivo com SACL, é aplicado o adesivo, que tem como função principal a formação do TAG de resina, que compõe a camada híbrida e é composto majoritariamente por dimetacrilatos hidrofóbicos, tais como bisfenol glicidil metacrilato (bisGMA), dimetacrilato de trietilenoglicol (TEGDMA), dimetacrilatos de uretano (UDMA) e ainda assim, uma pequena quantidade de monômero hidrofílico (HEMA) sendo então formado por monômeros mais viscosos e com maior peso molecular que são capazes de penetrar na superfície preparada pelo primer, preenchendo os espaços interfibrilares da rede colágena e criando prolongamentos de resina para promover a retenção micromecânica 3,5 . 


\section{TÉCNICA ÚMIDA EM DENTINA}

Diante da dificuldade de adesão em dentina, devido à quantidade significativa de matriz orgânica presente em sua composição, diversas estratégias têm sido estudadas a fim de preservar a integridade da interface adesiva para se obter uma estabilidade confiável da adesão em dentina. Nesse contexto, a técnica úmida em dentina consiste na manutenção da umidade da dentina após o condicionamento com ácido fosfórico, a fim de se manter a malha de colágeno íntegra para possibilitar uma adequada infiltração dos monômeros e evitar o colapso da rede colágena ${ }^{5}$. Portanto, a manutenção da umidade em dentina é obtida através da aplicação de um leve jato de ar e remoção do excesso de água com papel absorvente, podendo facilmente observar um aspecto brilhante na superfície tratada, o que indica uma umidade visível ${ }^{6}$.

\section{CLASSIFICAÇÃO QUANTO AOS PASSOS CLÍNICOS OPERATÓRIOS}

Frente à necessidade de simplificação dos procedimentos e com a intuição de se reduzir o tempo clínico de aplicação dos procedimentos odontológicos, nos sistemas adesivos isto foi realizado diminuindo o número de passos clínicos através da união, em um único frasco, do conteúdo do primer e do adesivo 7 .

Assim, os SACL podem ainda ser classificados como de dois ou três passos, a depender da apresentação do primer, que como mencionado anteriormente, pode estar combinado ou não com o adesivo em um único frasco. Dessa forma, os SACL de três passos são compostos por ácido fosfórico, primer e adesivo, que se encontram em frascos separados, sendo todos os passos da aplicação realizados isoladamente. Já quando se trata de SACL de dois passos, primer e adesivo encontram-se em uma única solução e são aplicados no mesmo momento após o condicionamento ácido (figura 03) 4,8 . 

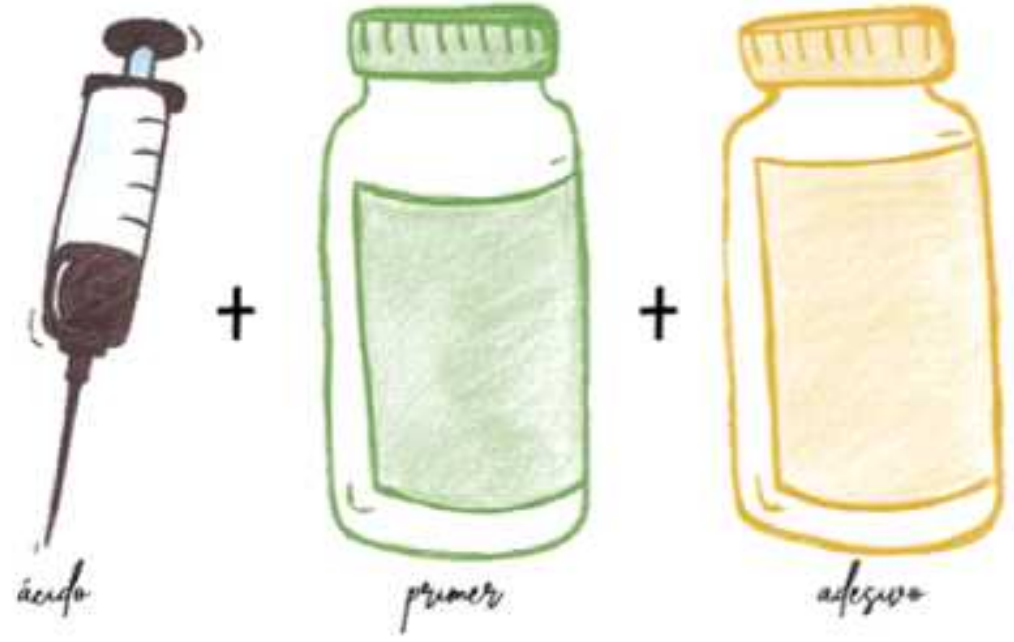

Figura 01: ilustração da apresentação de um SACL de três passos.

Fonte: autores, 2021.
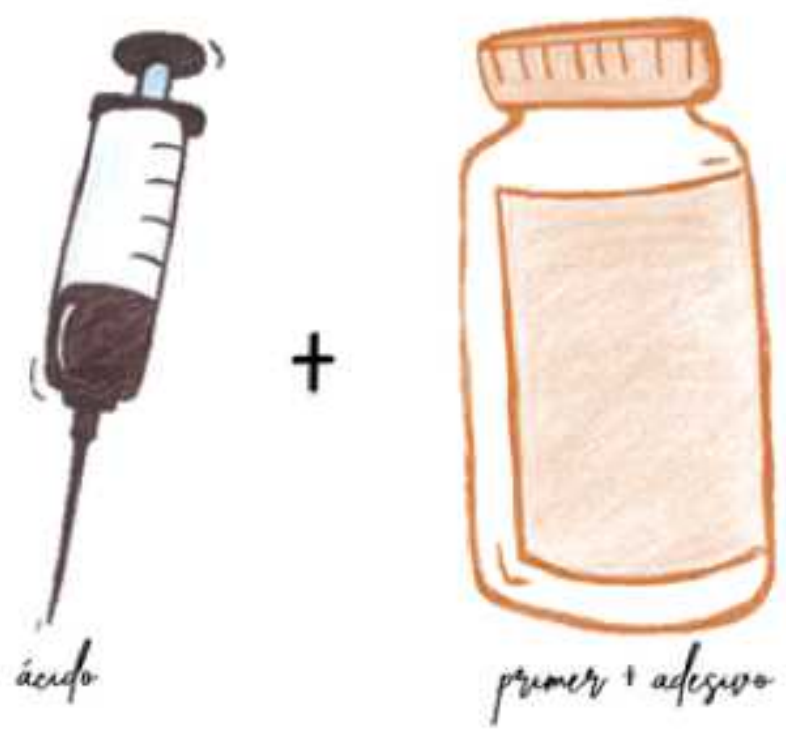

Figura 02: ilustração da apresentação de um SACL de dois passos.

Fonte: autores, 2021. 


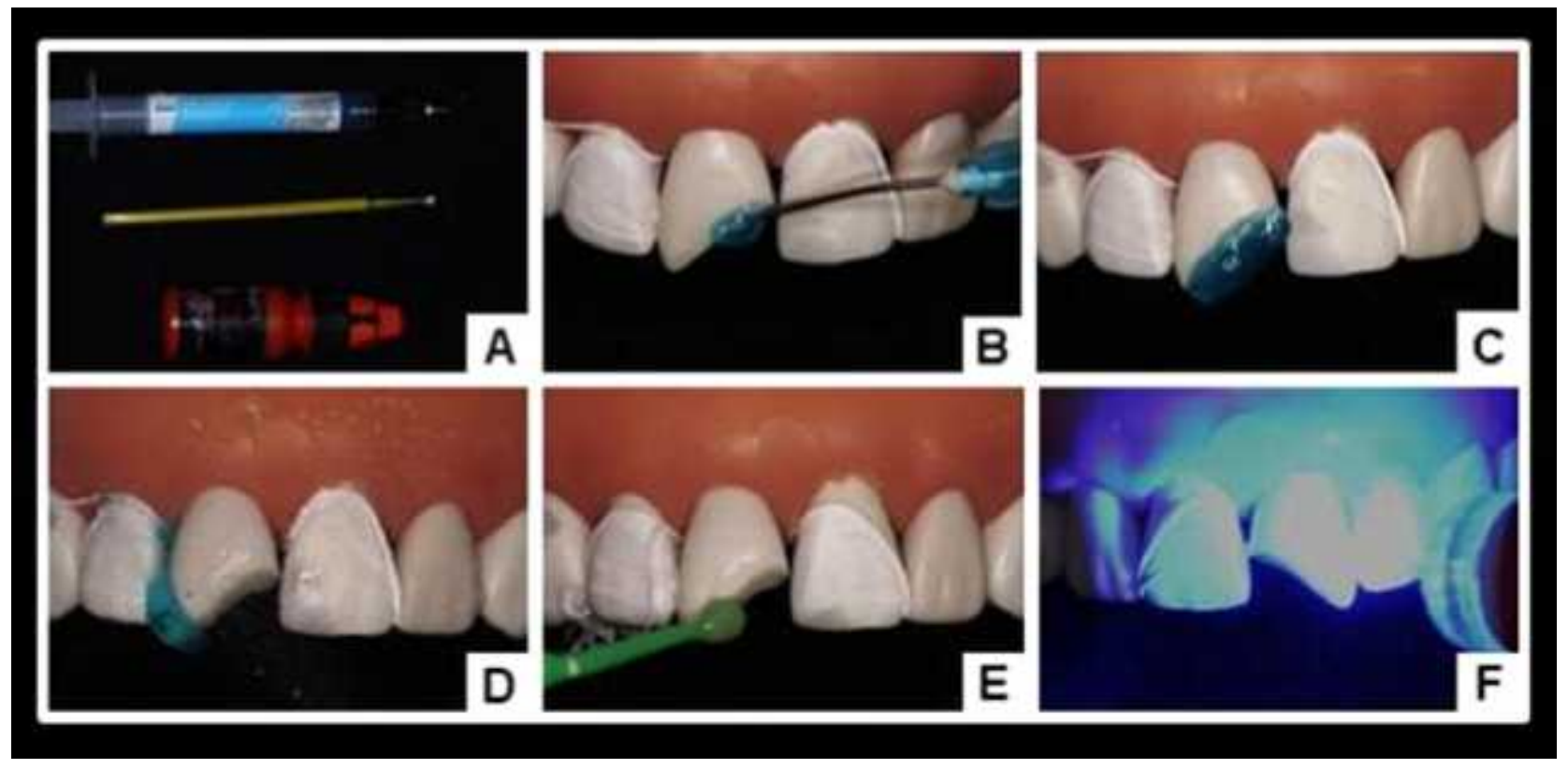

Figura 03: procedimento adesivo com SACL de dois passos. A - SACL de dois passos; B - Aplicação do ácido fosfórico 37\%; C - Ácido fosfórico aplicado; D - Lavagem da área condicionada; E - Aplicação do adesivo; F - fotopolimerização.

Fonte: autores, 2021. 


\section{REFERÊNCIAS}

1. OLIVEIRA, N. A. et al. Sistemas adesivos: conceitos atuais e aplicações clínicas. Revista Dentística online, v. 9, n. 19, p. 6-14, 2010.

2. PERDIGÃO, J. Dentin bonding-Variables related to the clinical situation and the substrate treatment. Dental Materials, v. 26, n. 2, p. e24-37, fev. 2010.

3. Anusavice, K. J., Shen, C., \& Rawls, H. R. (Eds.). (2012). Phillips' science of dental materials. Elsevier Health Sciences.

4. Reis, A., \& Loguercio, A. D. (2a Ed). (2021). Materiais dentários diretos: dos fundamentos à aplicação clínica. Santos.

5. Pashley, D. H., Tay, F. R., Breschi, L., Tjäderhane, L., Carvalho, R. M., Carrilho, M., \& Tezvergil-Mutluay, A. (2011). State of the art etch-and-rinse adhesives. Dental materials, 27(1), 1-16.

6. Reis, A. D., Loguercio, M., Schroeder, I., Luque-Martinez, D. \& Masterson, L. C. (2015). Does the adhesive strategy influence the post-operative sensitivity in adult patients with posterior resin composite restorations?: A systematic review and meta-analysis. Dental Materials, 31: 1052-1067.

7. Arinelli, A. M. D., Pereira, K. F., Prado, N. A. S., \& Rabello, T. B. (2016). Sistemas adesivos atuais. Revista Brasileira de Odontologia, 73(3), 242.

8. Ozer, F., \& Blatz, M. B. (2013). Self-etch and etch-and-rinse adhesive systems in clinical dentistry. Compendium of continuing education in dentistry (Jamesburg, NJ: 1995), 34(1), 12-4. 


\section{Capitulo3}

\section{ADESIVOS AUTOCONDICIONANTES}

s sistemas adesivos autocondicionantes (SAA) apresentam o diferencial dos sistemas de condicionamento e lavagem, a redução do passo clínico de condicionamento de superfície, uma vez que apresentam em sua composição, monômeros acídicos ${ }^{1}$.

Dessa maneira, a não utilização de um agente condicionante em superfície dentária possibilita uma técnica operatória mais simplificada e menos sensível à umidade presente em dentina, por exemplo2. Uma vantagem desse tipo de material é que gera uma menor sensibilidade pós operatória relatada na literatura ${ }^{3}$.

Esses adesivos possuem a vantagem de ao passo que é aplicado, quando a desmineralização e difusão do mesmo ocorrem concomitantemente garantem uma completa penetração do material em questão ${ }^{4}$. 


\section{COMPOSIÇÃO QUÍMICA}

Estes adesivos apresentam componentes tais como: primere adesivo.

Primer: contém monômeros hidrofílicos com a presença de grupamentos funcionais. Apresenta em sua composição o 2 - hidroxietil metacrilato (HEMA), sendo esse importante devido sua característica hidrofílica, juntamente à características químicas próximas aos dos solventes. Os monômeros acídicos também estão presentes na composição dos primers, conferindo à esses a característica de condicionamento concomitante com o embricamento do adesivo, são eles Fenil-P, 10metacriloiloxidecil dihidrogenofosfato (10-MDP), brometo de metacriloiloxidodecilpiridínio (MDPB), 4-trimetilpiridínio trimetil (MDPB). anidrido (4-META), ácido 4-metacriloiloxietil trimelítico (4-MET), ácido 11-metacriloiloxi-1,1-undecanedicarboxílico (MAC-10), 4acriloiloxietil trimelitato anidrido (4-AETA), di-hidrogenofosfato de 2metacriloiloxietil (MEP), metacrilatos de fosfato, ácido fosfônico de éter acrílico e outros ésteres de ácido fosfórico ${ }^{5}$. Os monômeros acídicos possuem em sua estrutura química a presença de um grupamento metacrilato insaturado capaz de se copolimerizar com outros monômeros de mesma natureza presentes na resina/adesivo, além disso possuem outro grupamento na extremidade de sua molécula, um grupamento capaz de reagir com silício, vidro e até mesmo cálcio presente em dentina ou esmalte, otimizando a união desses materiais nestes substratos dentários. Os solventes presentes nestes SAA podem ser de 3 tipos: etanol, água e cetona, esses desempenham função de otimizar o molhamento desses materiais no dente 6 .

Adesivo: tem por função principal a formação do TAG de resina, que compõe a camada híbrida. Sendo composto por monômeros dimetacrilatos com natureza hidrofóbica, tais como bisfenol glicidil metacrilato (bis-GMA), Dimetacrilato de trietilenoglicol (TEGDMA), dimetacrilatos de uretano (UDMA) e ainda assim, uma pequena quantidade de HEMA em sua composição ${ }^{6}$. 
Iniciadores: sistema formado por uma molécula fotossensível e um iniciador químico para realização do processo de fotopolimerização ${ }^{6}$.

Partículas de carga: podem melhorar a propriedade mecânica do mesmo, bem como tem função de regular a viscosidade do material. Essas são as sílicas de tamanho nanométrico ${ }^{6}$.

\section{CLASSIFICAÇÃO QUANTO AOS PASSOS CLÍNICOS OPERATÓRIOS}

Os SAAs podem vir com duas etapas de aplicação, bem como apenas uma, que pode também ser conhecido como adesivos "all-in-one". Nos de duas etapas, o primer e adesivo vem em frascos de aplicação separados (figura 01) e o de uma etapa contém os dois componentes em um só frasco de aplicação ( Figura 02) ${ }^{7}$.

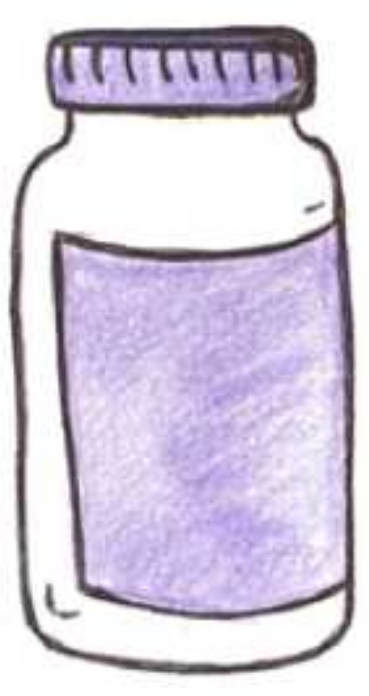

Primer

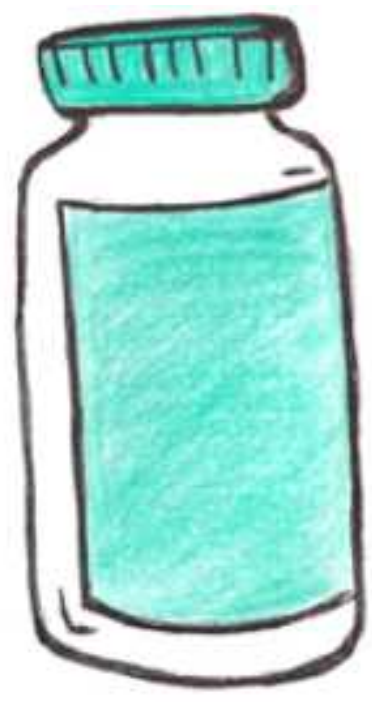

Adesivo

Figura 01: Adesivo autocondicionante de dois passos, onde em um frasco contém o primer e em outro o adesivo propriamente dito

Fonte: autores, 2021 


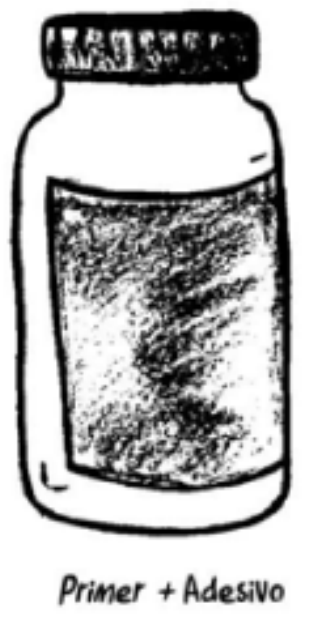

Figura 02: A desivo autocondicionante de um passo, onde nele contém componentes do primer juntamente com monômeros hidrofóbicos em um só frasco.

Fonte: autores, 2021

\section{CLASSIFICAÇÃO QUANTO AO PH}

Os SAAs podem ser classificados de acordo com pH, e essa classificação implica diretamente na forma com que esses adesivos se comportam no substrato dentário ${ }^{1,8}$.

- Ultraleve $(\mathrm{pH}>2,5)$ : é gerada uma penetrabilidade à nível nanométrico, que pode ser denominada nanointeração ${ }^{1}$.

- Leve $(\mathrm{pH} \approx 2,0)$ : ocorre uma penetração deaproximadamente $1 \mu \mathrm{m}^{1}$.

- Intermediário ( $\mathrm{pH}$ entre 1,0 e 2,0): penetração entre 1 e $2 \mu \mathrm{m}^{1}$.

- Forte $(\mathrm{pH} \leq 1,0)$ : imbricamento de até $4 \mu \mathrm{m}^{1}$. 


\section{UNIÃO AO DENTE}

O processo de união dos SAA em dente pode ocorrer por meio de embricamento micromecânico adicionado com ligação química do grupamento funcional presente nos monômeros acídicos oriundos do primer, essa característica pode conferir uma maior durabilidade do processo adesivo. Entretanto, o comportamento clínico dos SAAs é diferente a depender se ocorre em substrato adamantino ou em dentina. Ao passo que ocorre aplicação ativa, em dentina, os monômeros acídicos desmineralizam a superfície e a penetram, dessa forma os grupamentos funcionais presentes nesses se ligam ao mineral cálcio presente no dente, sendo essa união de duas formas. Em esmalte, para que se tenha um melhor desempenho clínico, estudos demonstram que é necessário o condicionamento com ácido fosfórico, previamente à aplicação do SAA 5 . Nesta formação da camada híbrida há uma formação de uma zona de resistência ácido-base logo abaixo da região de hibridização, em dentina, sendo resistente à desafios ácidos e bases, podendo desempenhar um importante papel na prevenção de cáries secundárias. Já em esmalte, esta zona é formada na própria camada híbrida 9 . 


\section{REFERÊNCIAS}

1. Van Meerbeek, B., Yoshihara, K., Yoshida, Y., Mine, A. J. D. M. K. L. V. L., De Munck, J., \& Van Landuyt, K. L. (2011). State of the art of self-etch adhesives. Dental materials, 27(1), 17-28.

2. Peumans, M., Kanumilli, P., De Munck, J., Van Landuyt, K., Lambrechts, P., \& Van Meerbeek, B. (2005). Clinical effectiveness of contemporary adhesives: a systematic review of current clinical trials. Dental materials, 21(9), 864-881.

3. Perdigao, J., Geraldeli, S., \& Hodges, J. S. (2003). Total-etch versus self-etch adhesive: effect on postoperative sensitivity. The Journal of the American Dental Association, 134(12), 1621-1629.

4. Carvalho, R. M., Chersoni, S., Frankenberger, R., Pashley, D. H., Prati, C., \& Tay, F. R. (2005). A challenge to the conventional wisdom that simultaneous etching and resin infiltration always occurs in self-etch adhesives. Biomaterials, 26(9), 1035-1042.

5. Giannini, M., Makishi, P., Ayres, A. P. A., Vermelho, P. M., Fronza, B. M., Nikaido, T., \& Tagami, J. (2015). Self-etch adhesive systems: a literature review. Brazilian dental journal, 26(1), 3-10.

6. Anusavice, K. J., Shen, C., \& Rawls, H. R. (Eds.). (2012). Phillips' science of dental materials. Elsevier Health Sciences.

7. Van Landuyt, K. L., Mine, A., De Munck, J., Countinho, E., Peumans, M., Jaecques, S., ... \& Van Meerbeek, B. (2008). Technique sensitivity of water-free one-step adhesives. Dental Materials, 24(9), 1258-1267.

8. Yamauchi, K., Tsujimoto, A., Jurado, C. A., Shimatani, Y., Nagura, Y., Takamizawa, T., ... \& Miyazaki, M. (2019). Etch-and-rinse vs self-etch mode for dentin bonding effectiveness of universal adhesives. Journal of oral science, 18-0433.

9. Tsuchiya, S., Nikaido, T., Sonoda, H., Foxton, R. M., \& Tagami, J. (2004). Ultrastructure of the dentin-adhesive interface after acid-base challenge. Journal of Adhesive Dentistry, 6, 183-190. 


\section{Capitulo 4}

\section{ADESIVOS UNIVERSAIS}

s sistemas adesivos atuais têm como objetivos principais diminuir a sensibilidade da técnica e o número de passos clínicos precisos para o processo de adesão do material restaurador ao dente. Nessa perspectiva, destaca-se os sistemas adesivos universais (SAU).

Estes, por sua vez, aderem às estruturas dentais utilizando a técnica de condicionamento ácido total, auto ou seletivo. Além disso, alguns adesivos universais também tem a capacidade de se aderir a diversos substratos, incluindo resina composta, cerâmica de vidro, zircônia e ligas metálicas, sem a necessidade de utilizar primers adicionais. $A$ multifuncionalidade proporcionada pelos SAU fornece uma perspectiva nova e simplificada para a união entre resinas e vários substratos 1. Sabe-se que a eficácia desses materiais diante do esmalte dentário necessita do condicionamento ácido que proporciona a maior resistência de união ao mesmo ${ }^{2}$. 


\section{COMPOSIÇÃO QUÍMICA}

Os SAUs apresentam composição idêntica aos autocondicionantes de um (figura 01) frasco onde contém monômeros acídicos, solventes e monômeros metacrílicos ${ }^{3}$.

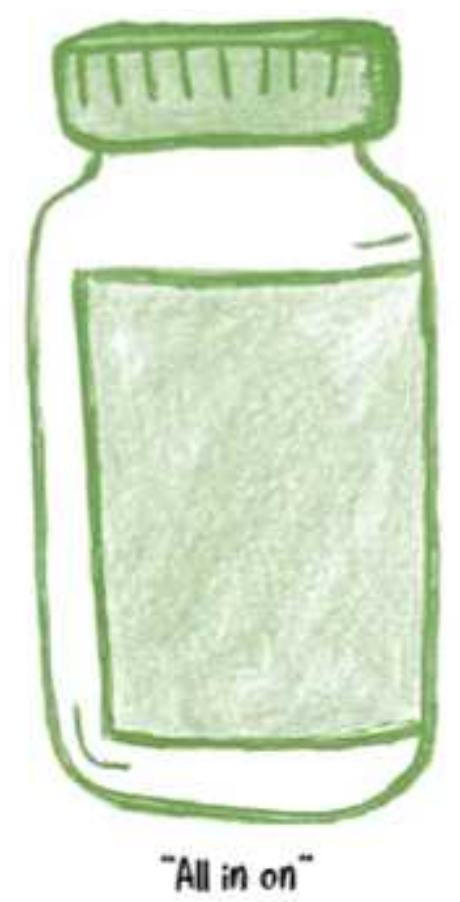

Figura 01: Apresentação comercial dos adesivos universais, em um só frasco. Fonte: autores, 2021

\section{CLASSIFICAÇÃO QUANTO AOS PASSOS CLÍNICOS OPERATÓRIOS}

Esses sistemas adesivos, podem ser utilizados pelas técnicas do condicionamento seletivo, do condicionamento ácido prévio ou do autocondicionamento, concedendo um maior número de alternativas ao profissional, que poderá escolher o procedimento adesivo mais adequado a cada situação 4 . 


\section{CLASSIFICAÇÃOQUANTO AO pH}

A maioria dos SAU enquadram-se nas categorias ultra-suave ( $\mathrm{ph}>2,5$ ) e suave $(\mathrm{ph}=2 \text { ) e, mais raros, agressividade meia forte (ph entre } 1 \text { e 2) })^{5,6}$.

\section{UNIÃO AO DENTE}

\section{Esmalte}

Os SAU usados com a estratégia do sistema autocondicionante, por serem menos agressivo, limita sua capacidade de desmineralizar totalmente $o$ esmalte, resultando em micro porosidades retentivas inadequadas, no entanto, já se sabe que a adesão com estratégia sistema convencional a longo prazo tem resultados significativamente melhores. Com isso surgiu vários métodos para melhorar as características da união resina/esmalte com os SAU, como por exemplo, a aplicação de camadas duplas do SAU para melhorar a resistência de união ao esmalte com a estratégia sistema convencional, possivelmente devido à maior espessura e melhores propriedades mecânica da camada híbrida ${ }^{3}$.

\section{Dentina}

Algumas pesquisas demonstram que com os SAU o tipo de estratégia adesiva pouco ou nada interfere na adesão na dentina. Porém, em estudos in vitro com o adesivo universal (All-bond Universal da BISCO) demonstrou que aderido à dentina com uma estratégia do sistema adesivo autocondicionante provoca uma maior resistência de união, mas com uma considerável heterogeneidade, ao contrário da estratégia sistema adesivo convencional que resulta numa maior estabilidade das características ao longo prazo ${ }^{6}$. 


\section{REFERÊNCIAS}

1. Pires, C. W., Lenzi, T. L., Soares, F. Z. M., \& Rocha, R. D. O. (2019). Bonding of universal adhesive system to enamel surrounding real-life carious cavities. Brazilian oral research, 33.

2. Tsujimoto, A., Barkmeier, W. W., Takamizawa, T., Wilwerding, T. M., Latta, M. A., \& Miyazaki, M. (2017). Interfacial characteristics and bond durability of universal adhesive to various substrates. Operative dentistry, 42(2), E59-E70.

3. Arinelli, A. M. D., Pereira, K. F., Prado, N. A. S., \& Rabello, T. B. (2016). Sistemas adesivos atuais. Revista Brasileira de Odontologia, 73(3), 242.

4. Avelar, W. V., Medeiros, A. F., Campos, F., Vasconcelos, R. G., \& Vasconcelos, M. G. (2019). Sistemas adesivos universais: composição, indicações, vantagens e desvantagens. Rev. Salusvita (Online), 155-175.

5. Tsujimoto, A., Barkmeier, W. W., Takamizawa, T., Watanabe, H., Johnson, W. W., Latta, M. A., \& Miyazaki, M. (2017). Comparison between universal adhesives and two-step self-etch adhesives in terms of dentin bond fatigue durability in self-etch mode. European journal of oral sciences, 125(3), 215-222.

6. Nagarkar, S., Theis-Mahon, N., \& Perdigão, J. (2019). Universal dental adhesives: Current status, laboratory testing, and clinical performance. Journal of Biomedical Materials Research Part B: Applied Biomaterials, 107(6), 2121-2131. 


\section{Capitulo5}

\section{MECANISMOS DE DEGRADAÇÃO DA INTERFACE DE UNIÃO DENTINA/ADESIVO}

o procedimento adesivo realizado em dente há tendência que ocorram mecanismos de degradação, principalmente com adesivos de condicionamento e lavagem no substrato da dentina, sendo que esses podem ser de 3 tipos: degradação polimérica, degradação de partículas de carga, degradação do colágeno ${ }^{1}$.

\section{DEGRADAÇÃO POLIMÉRICA}

O material resinoso de escolha no processo restaurador influencia diretamente na longevidade da restauração, assim sendo, a característica química primordial para aumentar a estabilidade restauradora seria um adesivo que possua alta hidrofobia, pois quanto maior esta característica, menor a susceptibilidade do mesmo apresentar sorção e solubilidade ${ }^{2}$. 
Assim sendo, a presença de água na interface de união induz quebra de ligações entre os monômeros, dessa forma quanto mais hidrofílico o monômero for, maior o risco à degradação, à exemplo disso o monômero 2- hidroxietil metacrilato (HEMA), que apresenta uma maior hidrofilicidade e tende a degradar mais. Além disso, um fator que influencia diretamente neste tipo de degradação trata-se da polimerização bem efetuada, pois sabe-se que o grau de conversão é inversamente proporcional ao mecanismo de degradação polimérica ${ }^{3}$.

\section{DESPRENDIMENTO DAS PARTÍCULAS DE CARGA}

As partículas de carga fazem parte da composição do adesivo visando melhorar a viscosidade deste material, além de originar uma resistência à fadiga do mesmo 4 . Estas partículas se unem aos monômeros por meio da ação do silano, porém a hidrólise do silano pode causar o desprendimento dessas partículas e gerar o enfraquecimento da camada de adesivo, além de deixar a região mais suscetível à entrada de mais água, aumentando a degradação ${ }^{5}$.

\section{DEGRADAÇÃO DO COLÁGENO}

Este tipo de degradação ocorre mais frequentemente quando se usa adesivos que necessitam de um condicionamento prévio, assim sendo após realizar-se o uso de ácido fosfórico em dentina há uma desmineralização de aproximadamente $8 \mu \mathrm{m}$, sendo que o adesivo consegue infiltrar apenas $6 \mu \mathrm{m}$, restando uma pequena área de fibra de colágeno exposta que continuará desnuda. Assim sendo, esta região é 
alvo de ação de enzimas endógenas, tais como metaloproteinases de matriz (MMPs) e as Catepsinas (CTPs), que irão degradar o colágeno6,7. Essas enzimas são ativadas quando se tem um pH reduzido, isso vai ocorrer quando se tem a aplicação do agente condicionante 7 .

\section{FATORES QUE INFLUENCIAM NA LONGEVIDADE DAS RESTAURAÇÕES}

Deve-se salientar que o excesso de umidade ou a remoção de água em demasia, na dentina pode gerar falha de união à longo prazo (REIS, 2021). O excesso de água pode facilitar o fenômeno de separação de fases, ou seja, não completa penetração dos monômeros dimetacrilatos, pois esses não possuem afinidade com a água; além disso ocorre uma polimerização mais dificultada ${ }^{8}$. Quando se seca a dentina em excesso ocorre um colabamento do colágeno exposto após o condicionamento ácido, diminuindo bastante o espaço interfibrilar, assim sendo, não há um embricamento adequado dos monômeros adesivo, o que pode gerar uma falha na formação da camada híbrida 8 .

A forma de aplicação do adesivo é outro fator que deve ser levado em consideração, pois a aplicação ativa, ou seja, vigorosa, pode levar a uma melhor penetração do adesivo ${ }^{9}$. Além disso, o micro pincel utilizado na aplicação do mesmo influencia diretamente no processo de união, tendo em vista que algumas marcas comerciais deixam a desejar na estabilidade dos pelos e muitas vezes eles se deslocam contaminando a cavidade ${ }^{10}$. 


\section{REFERÊNCIAS}

1. Feitosa, V. P., Leme, A. A., Sauro, S., Correr-Sobrinho, L., Watson, T. F., Sinhoreti, M. A., \& Correr, A. B. (2012). Hydrolytic degradation of the resin-dentine interface induced by the simulated pulpal pressure, direct and indirect water ageing. Journal of Dentistry, 40(12), 1134-1143.

2. Sadek, F. T., Pashley, D. H., Nishitani, Y., Carrilho, M. R., Donnelly, A., Ferrari, M., \& Tay, F. R. (2008). Application of hydrophobic resin adhesives to acid-etched dentin with an alternative wet bonding technique. Journal of Biomedical Materials Research Part A: An Official Journal of The Society for Biomaterials, The Japanese Society for Biomaterials, and The Australian Society for Biomaterials and the Korean Society for Biomaterials, 84(1), 19-29.

3. Ferracane, J. L. (2006). Hygroscopic and hydrolytic effects in dental polymer networks. Dental Materials, 22(3), 211-222.

4. Reis, A., \& Loguercio, A. D. (2a Ed). (2021). Materiais dentários diretos: dos fundamentos à aplicação clínica. Santos.

5. Brackett, M. G., Li, N., Brackett, W. W., Sword, R. J., Qi, Y. P., Niu, L. N., ... \& Tay, F. R. (2011). The critical barrier to progress in dentine bonding with the etchand-rinse technique. Journal of dentistry, 39(3), 238-248.

6. Scaffa, P. M. C., Vidal, C. M. P., Barros, N., Gesteira, T. F., Carmona, A. K., Breschi, L., ... \& Carrilho, M. R. (2012). Chlorhexidine inhibits the activity of dental cysteine cathepsins. Journal of dental research, 91(4), 420-425.

7. Tjäderhane, L., Nascimento, F. D., Breschi, L., Mazzoni, A., Tersariol, I. L., Geraldeli, S., ... \& Pashley, D. H. (2013). Optimizing dentin bond durability: control of collagen degradation by matrix metalloproteinases and cysteine cathepsins. Dental Materials, 29(1), 116-135.

8. Hashimoto, M., Tay, F. R., Svizero, N. R., de Gee, A. J., Feilzer, A. J., Sano, H., ... \& Pashley, D. H. (2006). The effects of common errors on sealing ability of totaletch adhesives. Dental materials, 22(6), 560-568.

9. Albuquerque, M., Pegoraro, M., Mattei, G., Reis, A., \& Loguercio, A. D. (2008). Effect of double-application or the application of a hydrophobic layer for improved efficacy of one-step self-etch systems in enamel and dentin.

10. Mary, G., \& Jayadevan, A. (2016). Microbrush stamp technique to achieve occlusal topography for composite resin restorations-A technical report. Journal of Scientific Dentistry, 6(2), 76. 


\section{Capitulo6}

\section{BIOMATERIAIS DE PRESERVAÇÃO DA INTERFACE DE UNIÃO}

om o advento das resinas compostas, observou-se uma crescente busca pelas restaurações estéticas, porém, elas apresentam uma durabilidade reduzida, o que se deve à dificuldade de se estabelecer uma união efetiva entre a estrutura dentária e o material restaurador em questão ${ }^{1}$.

Nesse sentido, quando se utiliza Sistemas Adesivos de Condicionamento e Lavagem (SACL), essa união é tida como crítica em dentina, isto em razão de sua composição orgânica e da presença de umidade nos túbulos dentinários, além disso, a camada híbrida pode sofrer alguns mecanismos de degradação mediados por enzimas Metaloproteinases de Matriz (MMPs) e Cisteíno Catepsinas (CTPs), além de degradação polimérica e hidrolítica ${ }^{2,3}$.

Diante disso, diversas estratégias têm sido estudadas a fim de aperfeiçoar as propriedades mecânicas da camada híbrida e, 
consequentemente, minimizar a degradação desta, tais como os Agentes de Ligações Cruzadas (ALC), os Agentes Inibidores de MMPs e CTP (AI), Remineralizadores Biomiméticos (RB) e a Técnica Úmida Etanólica (TUE).

\section{AGENTES DE LIGAÇÕES CRUZADAS}

São compostos químicos capazes de realizar ligações químicas de diferentes tipos, tanto inter-colágeno, bem como intra-colágeno dentinário, exposto após o condicionamento ácido. Tem por ação principal a melhoria das propriedades mecânicas do colágeno presente na dentina, otimizando a camada híbrida formada, além disso por gerar diversos tipos de ligações químicas, nesse substrato, podem deixar a técnica adesiva menos sensível à utilização de jato de ar. Ademais, esses agentes também vão atuar como inibidores de metaloproteinases de matriz e cisteíno catpsinas. Os ALCs podem ser classificados quanto à sua origem em naturais e sintéticos 4,5 .

\section{Agentes de ligações cruzadas de origem natural}

O ALC mais bem estabelecido na literatura trata-se da proantocianidina, que é uma catequina oriunda da semente de uva. Sabe-se que essa molécula vai interagir com o colágeno por diversos tipos de ligações químicas, dentre eles tem-se a formação de ligações de hidrogênio, covalente estável, bem como hidrofóbicas. Além disso, pode-se formar um complexo de cálcio amorfo atuando como um agente remineralizador $4,5,6$.

Além disso, existem outros agentes naturais potenciais biomodificadores, tais como ácido tânico ${ }^{3}$, cardanol ${ }^{6}$, apigenina, ácido elágico, curcumina, hesperidina 7 , dentre outros. 
O mecanismo de interação desses agentes com o colágeno não é bem estabelecido, entretanto, acredita-se que seja por meio da presença do grupamento fenol da sua estrutura química com a amina presente na estrutura do colágeno ${ }^{4}$.

Agentes de ligações cruzadas de origem sintética

Existem dois principais agentes de origem sintética, que são eles o glutaraldeído que irá formar ligação do tipo aldeídica com o colágeno dentinário. Embora essas ligações sejam em quantidade reduzidas, são extremamente estáveis8. A literatura também relata a carboiimida, bem como a galardina 9,10 .

\section{INIBIDORES DE METALOPROTEINASES DE MATRIZ E CISTEÍNO CATEPCINAS}

São substâncias que apresentam capacidade de inibir as MMPs e CTPs, sendo a principal delas a clorexidina. A aplicação do inibidor pode ocorrer diretamente na superfície após o condicionamento ácido ou pode apresentar-se incorporada ao adesivo11.

\section{Clorexidina}

A clorexidina, uma protease sintética inibidora, atua como inibidor não específico de MMPs, modificando a estrutura tridimensional destas enzimas e quelando os íons metálicos, compostos fundamentais para a ativação enzimática e consequente atividade das MMPs. Dessa forma, inibem mais especificamente as MMPs-9, 8 ou 2, e ainda é capaz de inativar a atuação das CTPs. Ademais, esta substância possui uma elevada substantividade, o que possibilita a permanência dessa substância por um tempo adequado na superfície e cavidade bucal ${ }^{12}$. 


\section{REMINERALIZADORES BIOMIMÉTICOS}

A remineralização da interface adesiva vem sendo estudada a fim de substituir a água dos espaços intrafibrilares e das demais regiões ricas em água em que o adesivo não consegue infiltrar, por cristalitos de apatita. Logo, a partir disso, seria provável melhorar as propriedades mecânicas da interface adesiva e proteger a rede colágena da exposição aos possíveis desafios de degradação. Para tanto, os RBs têm sido pesquisados e atuam a partir do preenchimento do colágeno desmineralizado com nanopartículas de fosfato de cálcio amorfo estabilizadas por análogos biomiméticos de proteínas não colágenas que são caracterizados pela presença de ácido aspártico, ácido glutâmico e fosfoproteínas ${ }^{13}$.

Dentre eles, vêm sendo testados para a remineralização de interfaces adesivas o ácido poliacrílico ${ }^{14}$, ácido polivinilfosfônico ${ }^{15}$ e sódio trimetafosfato ${ }^{14}$ que podem ser capazes de promover a precipitação mineral na camada híbrida e, consequentemente, reduzir a degradação do colágeno exposto ao risco da degradação.

\section{Ácido poliacrílico}

Age como uma molécula de ligação ao cálcio, sendo empregado como um similar de proteínas não colágenas ácidas, como a proteína da matriz dentinária 1 para estabilizar as dimensões das fases amorfa do carbonato de cálcio e fosfato de cálcio ${ }^{14}$.

\section{Ácido polivinilfosfônico}

Trata-se de um polieletrólito que tem sido utilizado como análogo para proteínas da matriz de ligação ao colágeno, tais como as fosfoproteínas dentinárias ${ }^{15}$. 


\section{Sódio trimetafosfato}

Trata-se de um similar da fosfoforina que realiza ligações com as fibrilas colágenas e produz sítios fosforilados com cargas negativas que envolvem nanoprecursores e resultam na promoção de cristalites de apatita14.

\section{TÉCNICA ÚMIDA ETANÓLICA}

Dentre as diversas estratégias existentes para auxiliar na otimização das propriedades mecânicas e durabilidade da interface adesiva, a TUE surgiu como uma alternativa à técnica úmida convencional, sendo caracterizada pela substituição da água livre presente na dentina pelo etanol, um solvente em que não há a presença de água, através de uma desidratação química 16 .

Com a substituição da água pelo etanol, ocorrerá uma constrição do diâmetro da tripla hélice do colágeno, aumentando o espaço interfibrilar, o que viabiliza, desse modo, a penetração dos monômeros hidrofóbicos presentes no adesivo de maneira satisfatória16. A substituição da água pelo etanol remove o excesso de água livre na dentina, que corresponde a $75 \%$ da água total, deixando assim um ambiente mais propício para entrada de monômeros dimetacrilatos de característica hidrofóbica. Essa técnica permite o não uso do primer que contém HEMA, sendo assim, esse monômero que é principal responsável pela sorção e solubilidade da interface adesiva não é utilizado. Assim, a TUE possibilita a redução da degradação hidrolítica, proporcionando ainda uma melhora no processo de polimerização e um consequente aumento da longevidade das restaurações em resina composta 17 . 


\section{REFERÊNCIAS}

1. Pashley, D. H., Tay, F. R., Breschi, L., Tjäderhane, L., Carvalho, R. M., Carrilho, M., \& Tezvergil-Mutluay, A. (2011). State of the art etch-and-rinse adhesives. Dental materials, 27(1), 1-16

2 Breschi, L., Maravic, T., Cunha, S. R., Comba, A., Cadenaro, M., Tjäderhane, L., ... \& Mazzoni, A. (2018). Dentin bonding systems: From dentin collagen structure to bond preservation and clinical applications. dental materials, 34(1), 78-96

3 e Oliveira, L. V., Prado, M., de Menezes, L. R., Dias, C. T., Paulillo, L. A. M. S., \& da Silveira Pereira, G. D. (2015). Influência da camada híbrida na resistência à microtração de sistemas adesivos após armazenamento. Revista Brasileira de Odontologia, 71(2), 163

4 Bedran-Russo, A. K., Pauli, G. F., Chen, S. N., McAlpine, J., Castellan, C. S., Phansalkar, R. S., ... \& Leme, A. A. (2014). Dentin biomodification: strategies, renewable resources and clinical applications. Dental materials, 30(1), 62-76.

5 Mendes, T. A. D., Pascoal, S. C. D., Lemos, M. V. S., Santiago, S. L., \& Mendonça, J. S. (2019). Ácido tânico como agente biomodificador de dentina. Journal of Health \& Biological Sciences, $7(2$ (Abr-Jun)), 182-186.

6 Ferreira, A. C., Mendes, T. A. D., Lemos, M. V. S., Paula, D. M. M. D., Lima, K. E. R., \& Martins, L. F. B. (2020). Efeito Biomodificador de Diferentes Agentes de Ligações Cruzadas nas Propriedades Mecânicas do Colágeno Dentinário. Rev. bras. odontol, 1-5.

7 Lemos, M. V. S. (2020). Avaliação de agentes bioativos para o aprimoramento da interface de união em substrato dentinário.

8 Pinto, R. V., Gomes, P. S., Fernandes, M. H., Costa, M. E., \& Almeida, M. M. (2020). Glutaraldehyde-crosslinking chitosan scaffolds reinforced with calcium phosphate spray-dried granules for bone tissue applications. Materials Science and Engineering: C, 109, 110557.

9 Wang, Y., Zhang, W. X., \& Xi, Z. (2020). Carbodiimide-based synthesis of Nheterocycles: moving from two classical reactive sites to chemical bond breaking/forming reaction. Chemical Society Reviews, 49(16), 5810-5849.

10 Breschi, L., Martin, P., Mazzoni, A., Nato, F., Carrilho, M., Tjäderhane, L., ... \& Pashley, D. H. (2010). Use of a specific MMP-inhibitor (galardin) for preservation of hybrid layer. Dental materials, 26(6), 571-578. 
11 Montagner, A. F., Sarkis-Onofre, R., Pereira-Cenci, T., \& Cenci, M. S. (2014). MMP inhibitors on dentin stability: a systematic review and meta-analysis. Journal of dental research, 93(8), 733-743

12 dos Santos Junior, V. E., Dantas Gomes Lyra, J., Bizinoto Silva, M., Vilela Heimer, M., \& Rosenblatt, A. (2016). Mecanismo de ação da clorexidina sobre as enzimas metaloproteinases e sua repercussão clínica: um estudo de revisão. RFO UPF, 21(3), 306-311

13 Braga, R. R., \& Fronza, B. M. (2020). The use of bioactive particles and biomimetic analogues for increasing the longevity of resin-dentin interfaces: A literature review. Dental materials journal, 39(1), 62-68

14 Gu LS, Kim J, Kim YK, Liu Y, Dickens SH, Pashley DH, et al. A chemical phosphorylation-inspired design for Type I collagen biomimetic remineralization. Dent Mater 2010; 26: 1077-1089.

15 Lin HP, Lin J, Li J, Xu JH, Mehl C. In vitro remineralization of hybrid layers using biomimetic analogs. J Zhejiang Univ Sci B 2016; 17: 864-873.

16 Pashley, D. H., Tay, F. R., Carvalho, R. M., Rueggeberg, F. A., Agee, K. A., Carrilho, M., ... \& García-Godoy, F. (2007). From dry bonding to water-wet bonding to ethanol-wet bonding. A review of the interactions between dentin matrix and solvated resins using a macromodel of the hybrid layer. American journal of dentistry, 20(1), 7

17 Sadr, A., Ghasemi, A., Shimada, Y., \& Tagami, J. (2007). Effects of storage time and temperature on the properties of two self-etching systems. Journal of dentistry, 35(3), 218-225 


\section{Capitulo 7 \\ TÉCNICAS ADESIVAS}

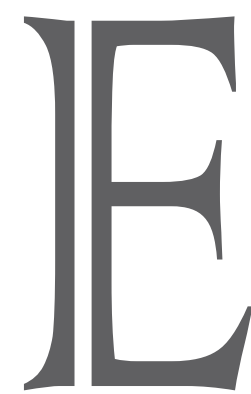

m cada situação clínica podemos indicar as técnicas adesivas e o tipo melhor indicado ${ }^{1}$.

\section{CAVIDADES RESTRITAS À ESMALTE}

São utilizadas em cavidades classe IV, recontorno cosmético, facetas diretas em resinas compostas, adição seletiva em resina composta e fechamento de diastemas. Deve-se optar por adesivos de condicionamento e lavagem, idealmente um de 3 passos, utilizando o ácido fosfórico previamente;

Passo à passo clínico de restaurações restritas em esmalte:

1. Realiza-se a profilaxia do substrato com pedra polmes e água;

2. Aplica-se o ácido fosfórico $37 \%$ por 30 segundos (figura 01); 


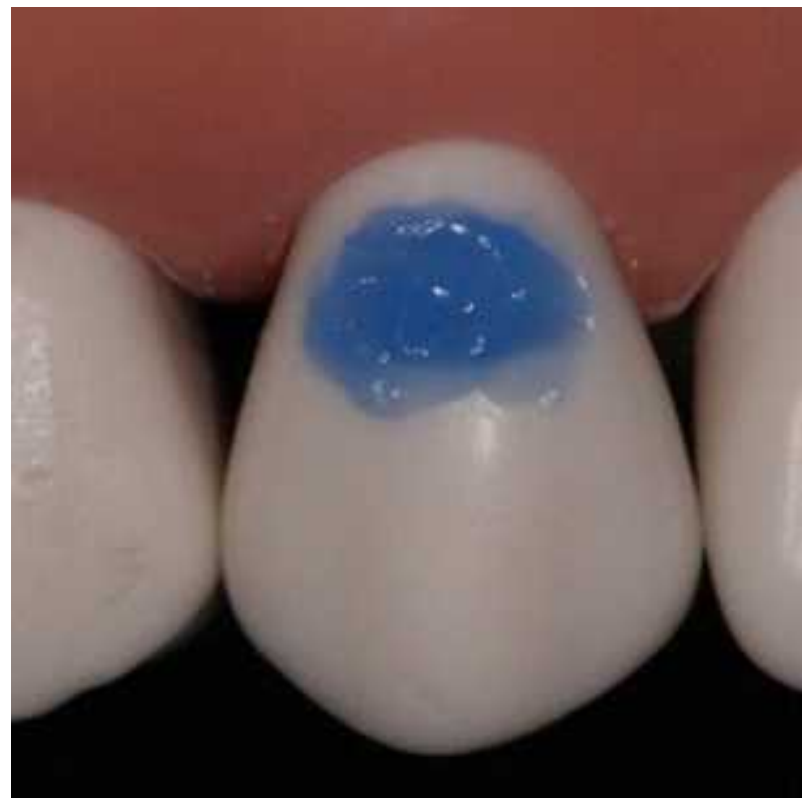

Figura 01: condicionamento dentário com ácido fosfórico 37\% (CONDAC- FGM) Fonte: autores, 2021.

3. Lava-se pelo dobro do tempo (figura 02);

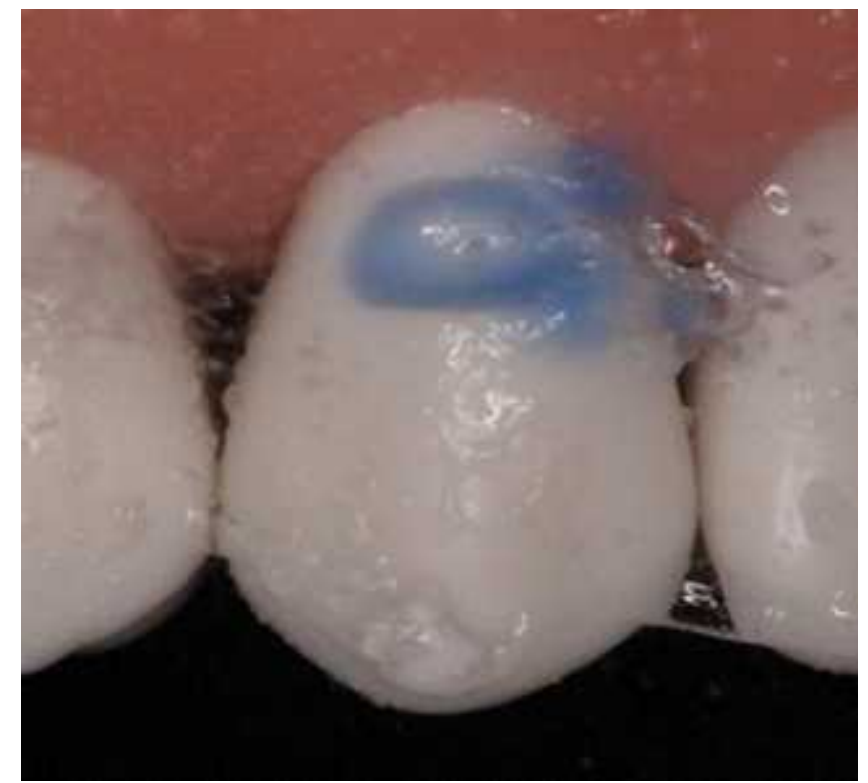

Figura 02: lavagem do agente condicionante por 60 segundos. Fonte: autores, 2021. 
4. Seca-se com jato de ar até observar-se um aspecto mais opaco do esmalte;

5. $O$ adesivo ou Bond é aplicado de maneira ativa, com auxílio de um micro pincel (figura 03);

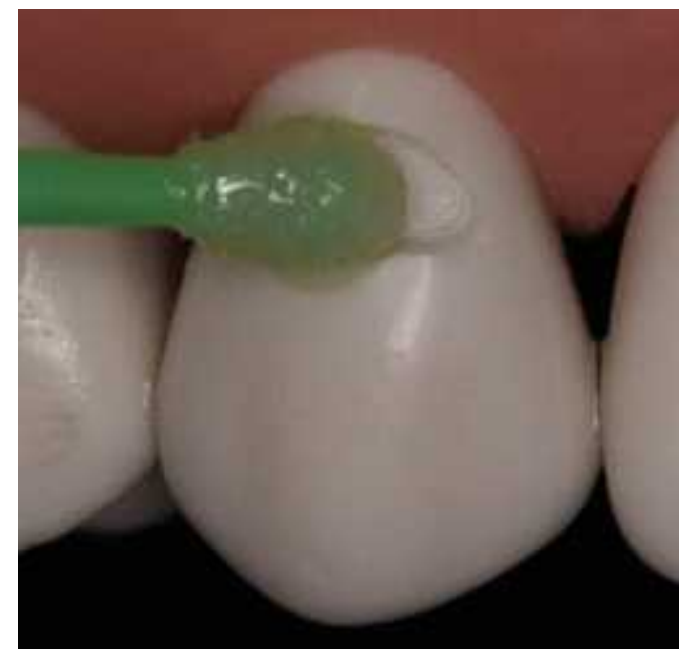

Figura 03: aplicação do adesivo Adesivo Adper ${ }^{T M}$ Scotchbond ${ }^{T M}$ Multiuso (3M) Fonte: autores, 2021.

6. Lança-se um jato de ar por 5 segundos;

7. Fotoativa-se pelo o tempo recomendado pelo fabricante (figura 04);

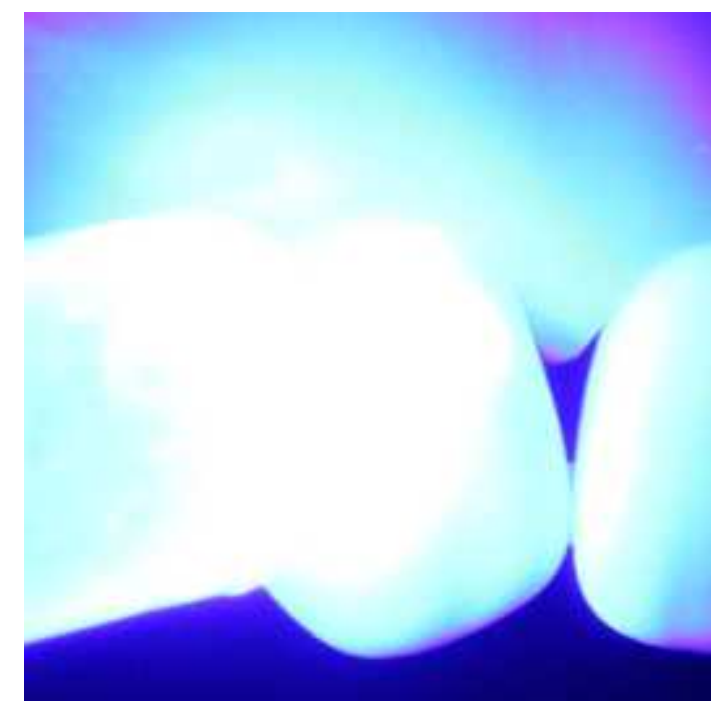

Figura 04: Fotoativação do adesivo.

Fonte: autores, 2021. 


\section{CAVIDADES RASAS ENVOLVENDO ESMALTE E DENTINA}

Quando se tem cavidades rasas, ou seja com exposição superficial de dentina, seja ela em dentes posteriores ou anteriores, pode-se lançar mão de adesivos de condicionamento total em esmalte e dentina. Em cavidades rasas tem-se uma menor concentração de túbulos dentinários e esses apresentam menor diâmetro, o que deixa o processo adesivo mais previsível para os adesivos de condicionamento e lavagem ${ }^{1}$.

Passo à passo clínico de adesivos de condicionamento e lavagem de 2 e 3 passos:

1. Realiza-se a profilaxia do substrato com pedra polmes e água;

2. Aplica-se o ácido fosfórico 37\% por 15 segundos em esmalte

3. E complementa-se aplicando o ácido fosfórico $37 \%$ por mais 15 segundos em dentina (Figura 06A);

4. Lava-se por um período de 30 à 60 segundos;

5. Secagem do dente com o uso do papel absorvente ou bolinha de algodão estéril (Figura 06B);

6. Aplica-se o sistema adesivo convencional

6.1 Convencional de 2 passos: aplica-se ativamente a primeira camada da solução contendo primer e bond, seguida de aplicação de jato de ar por 10 segundos 2 e aplicação da segunda camada.

6.2 Convencional de 3 passos: aplica-se ativamente o primer por 30 segundos, seguido de jato de ar por 10 segundos 2 , depois aplicação do bond (Figura 06C e 06D).

7. Fotoativação por período recomendado pelo fabricante. 

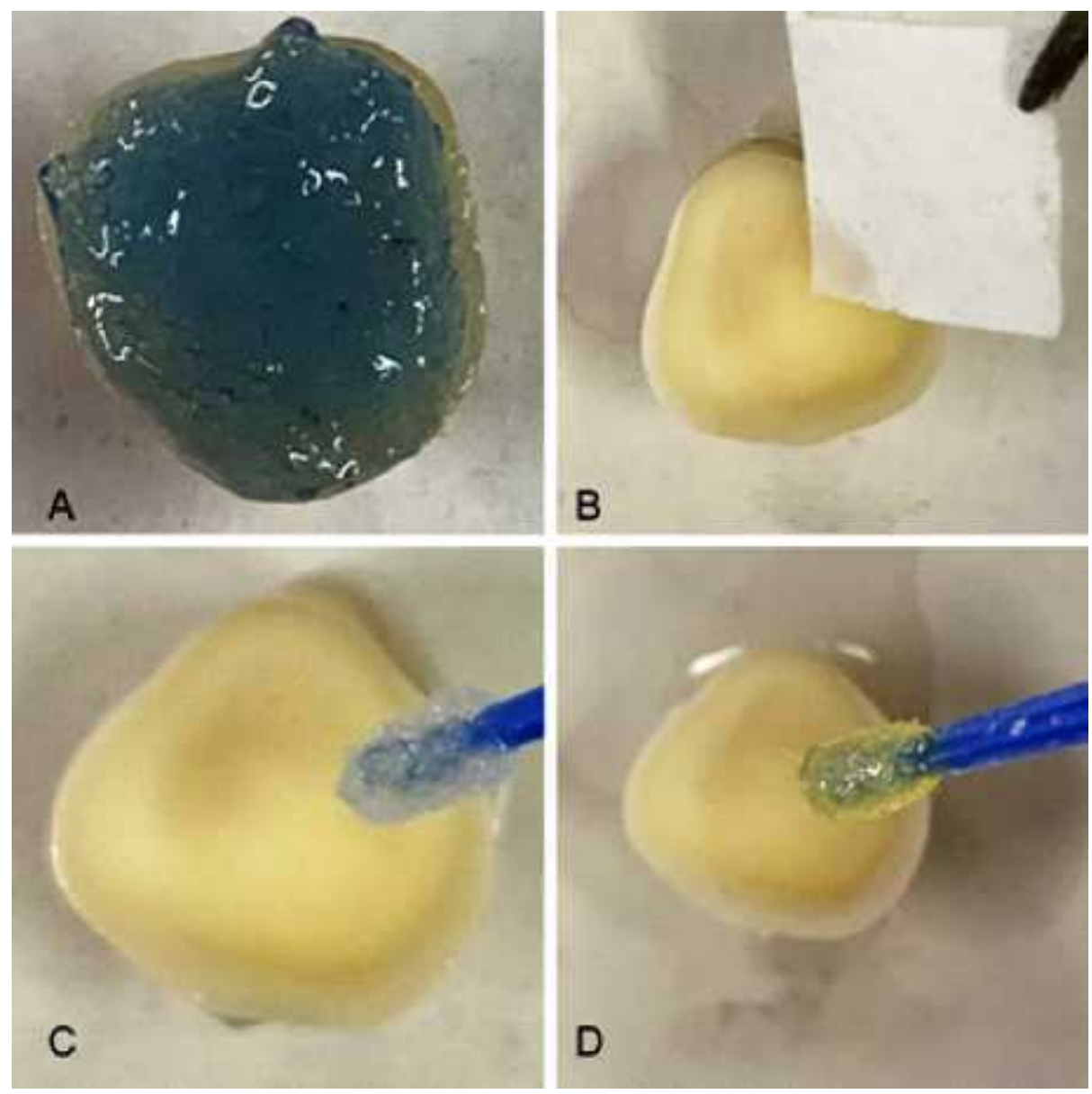

Figura 05: processo adesivo de um adesivo convencional de 3 passos, onde há aplicação de ácido fosfórico $37 \%(A)$, com secagem da dentina usando papel absorvente (B), seguido da aplicação do primer (C), posteriormente o bond (D).

Fonte: autores, 2021.

\section{QUANDO SE TEM CAVIDADES COM BORDAS EM ESMALTE COM MÉDIA OU GRANDE PROFUNDIDADE}

Quando há cavidade de média ou grande profundidade, em região anterior e posterior, onda haja a presença de bordos em esmalte, pode-se lançar mãos de adesivos com primer autocondicionante, de dois passos (figura 05) ou os adesivos universais, também conhecido por all-in-on ${ }^{3}$. 


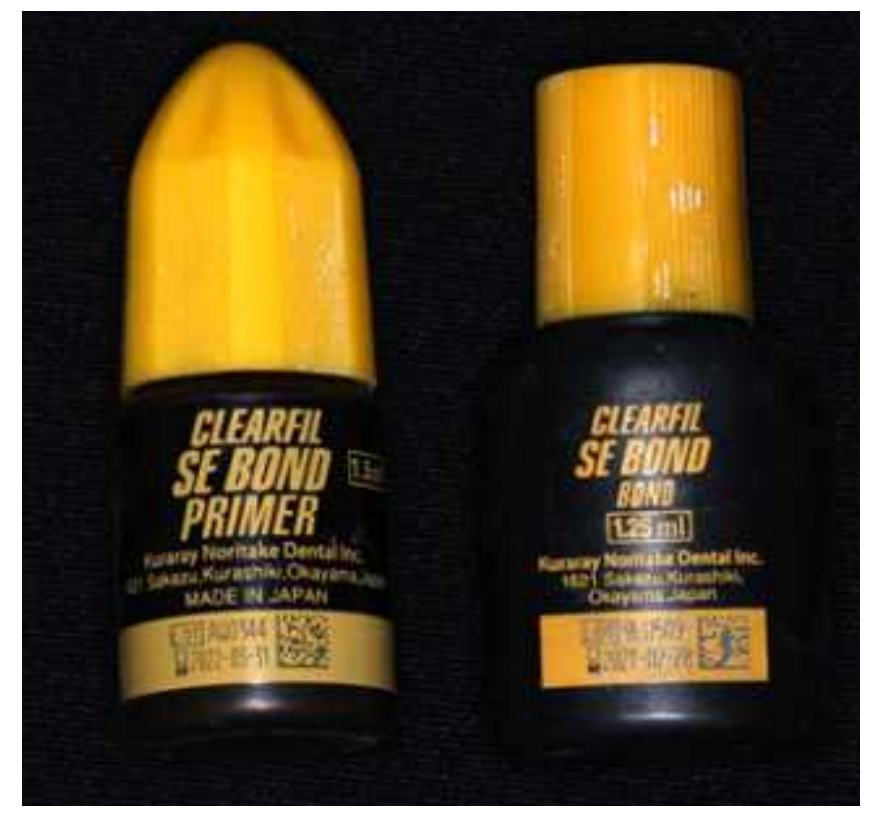

Figura 06: adesivo autocondicionante de 2 passos Clearfil SE Bond (Kuraray), considerado o "padrão ouro" dentre os autocondicionantes. Fonte: Autores, 2021.

Passo à passo clínico de adesivos autocondicionantes de 2 passos:

1. Profilaxia da cavidade com pedra polmes eágua;

2. Condicionamento seletivo em esmalte por 30 segundos, com ácido fosfórico $37 \%$.

3. Lavagem por 30 segundos.

4. Secagem de toda superfície, dentina e esmalte, com jato de ar;

5. Aplicar vigorosamente o primer por 20 segundos $^{4}$;

6. Aplicar o jato de ar por 20 segundos para evaporação do solvente 2,4

7. Aplicação do bond;

8. Jato de ar de 20 segundos 2,4;

9. Fotoativação por 20 segundos; 
Passo à passo clínico de adesivos autocondicionantes de 1 passo/ universal/ "all-in-on":

1. Profilaxia da cavidade com pedra polmes e água;

2. Condicionamento seletivo em esmalte por 30 segundos, com ácido fosfórico $37 \%$;

3. Lavagem por 30 segundos;

4. Secagem de toda superfície, dentina e esmalte, com jato de ar;

5. Aplicar o adesivo vigorosamente pelo tempo recomendado pelo fabricante, em média 20 segundos 2,4 ;

6. Jato de ar por 20 segundos, de maneira leve ${ }^{2,4}$;

7. Fotoativação.

\section{CONTAMINAÇÃO DURANTE O PROCESSO ADESIVO}

A técnica adesiva quer uma sensibilidade operatória acurada, visto que se torna o processo mais importante quando trata de restaurações diretas com resina composta. Idealmente requer um isolamento absoluto para minimizar risco de contaminação durante o processo restaurador. Assim sendo, quando se houver contaminação, a depender do passo que ocorra, tem-se maneiras diferentes de conduzir tal situação para a resolução. Caso a contaminação ocorra após o condicionamento ácido, tanto em esmalte quanto em dentina, deve-se lavar abundantemente ${ }^{6,7}$.

Quando a contaminação ocorrer após a aplicação do primer, para adesivos de condicionamento e lavagem de 3 passos; ou após primer e adesivo, para adesivos de condicionamento e lavagem de 2 passos, ocorrerá um grande comprometimento de resistência de união, assim faz-se necessário lavagem abundante, seguido de secagem e reaplicação do sistema adesivo 8 . 


\section{REFERÊNCIAS}

1. Hirata, R. (2017). Shortcuts in esthetic dentistry. Barcelona: Quintessence.

2. Ikeda, T., De Munck, J., Shirai, K., Hikita, K., Inoue, S., Sano, H., ... \& Van Meerbeek, B. (2008). Effect of air-drying and solvent evaporation on the strength of HEMA-rich versus HEMA-free one-step adhesives. Dental Materials, 24(10), 1316-1323.

3. Van Meerbeek, B., De Munck, J., Yoshida, Y., Inoue, S., Vargas, M., Vijay, P., ... \& Vanherle, G. (2003). Buonocore Memorial Lecture. Adhesion to enamel and dentin: Current status and future challenges. Operative dentistry, 28(3), 215235.

4. Cardoso, P. D. C., Loguercio, A. D., Vieira, L. C. C., Baratieri, L. N., \& Reis, A. (2005). Effect of prolonged application times on resin-dentin bond strengths. Journal of Adhesive Dentistry, 7(2).

5. Spreafico, D., Semeraro, S., Mezzanzanica, D., Re, D., Gagliani, M., Tanaka, T., ... \& Sidhu, S. K. (2006). The effect of the air-blowing step on the technique sensitivity of four different adhesive systems. Journal of Dentistry, 34(3), 237244.

6. El-Kalla, I. H., \& Garcia-Godoy, F. (1999). Effect of saliva contamination on micromorphological adaptation of single-bottle adhesives to etched enamel. The Journal of clinical pediatric dentistry, 24(1), 69-74.

7. Hewlett, E. R. (2003). Resin adhesion to enamel and dentin: a review. Journal of the California Dental Association, 31(6), 469-476.

8. Kaneshima, T., Yatani, H., Kasai, T., Watanabe, E. K., \& Yamashita, A. (2000). The influence of blood contamination on bond strengths between dentin and an adhesive resin cement. Operative Dentistry, 25(3), 195-201. 


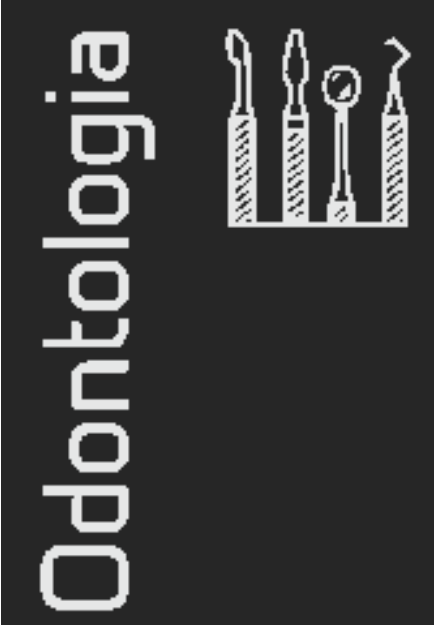

\section{SISTEMAS ADESIVOS EM ODONIOLOGIA: DOS PRINCÍPIOS DE UNIĀO À TÉCNICA CLÍNICA}

\section{Autores:}

Talita Arrais Daniel Mendes

Karlos Eduardo Rodrigues Lima

Vàgner Herton Silva Diógenes Júnior

Carlos lury Sant'Ana Furtado

Gabriela Soares Santana

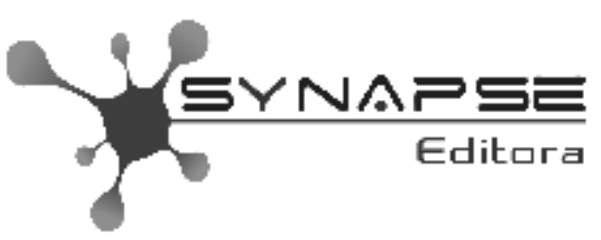

Compartilhando conhecimento 


\section{Sobre os Autores}

\section{Talita Arrais Daniel Mendes}

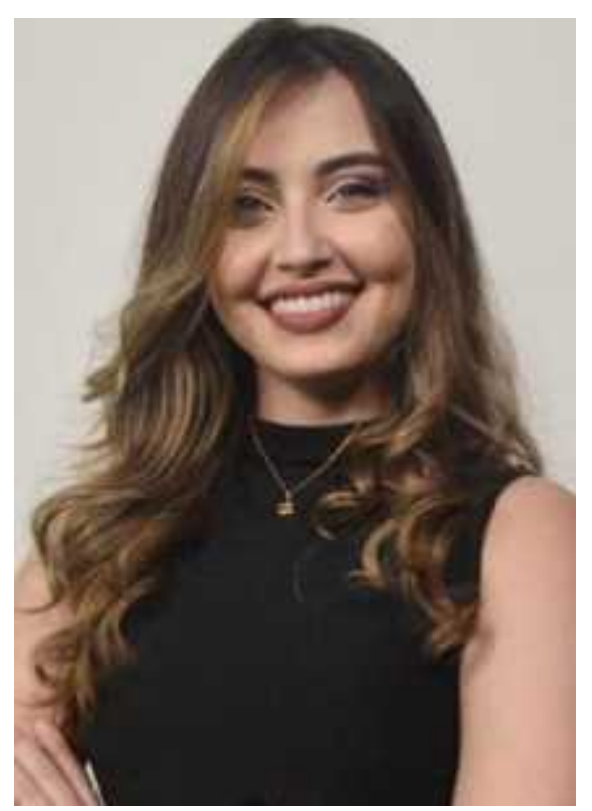

Graduada em Odontologia pela Universidade Federal do Ceará;

Mestra em Odontologia pela Universidade Federal do Ceará;

Especialista em Prótese Dental pela Academia Cearense de Odontologia;

Especialista em Periodontia pela Associação Brasileira de Odontologia;

Doutoranda em Odontologia pela Universidade Federal do Ceará.

\section{Karlos Eduardo Rodrigues Lima}

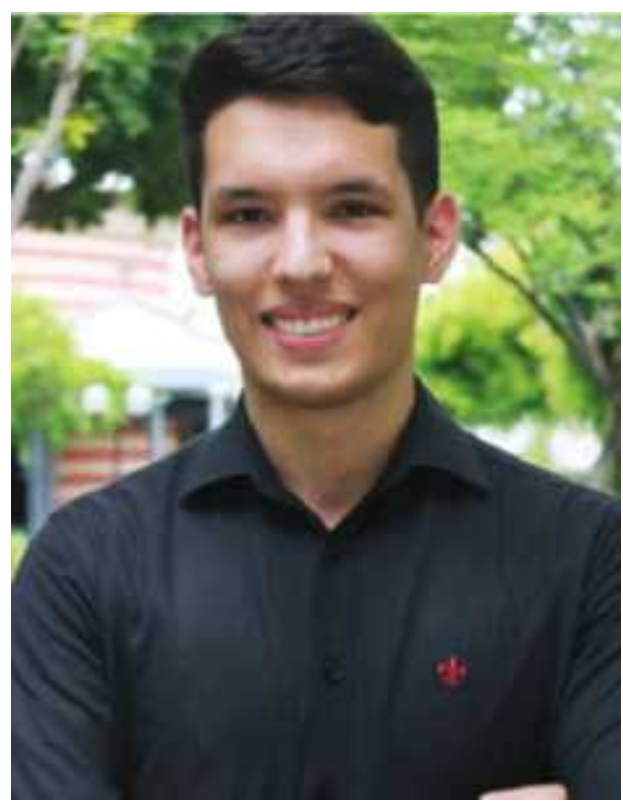

Graduando em Odontologia pelo Centro Universitário Católica de Quixadá;

Membro do Grupo de Extensão em Odontologia Preventiva e Restauradora do Centro Universitário Católica de Quixadá. 


\section{Sobre os Autores}

\section{Vágner Herton Silva Diógenes Júnior}

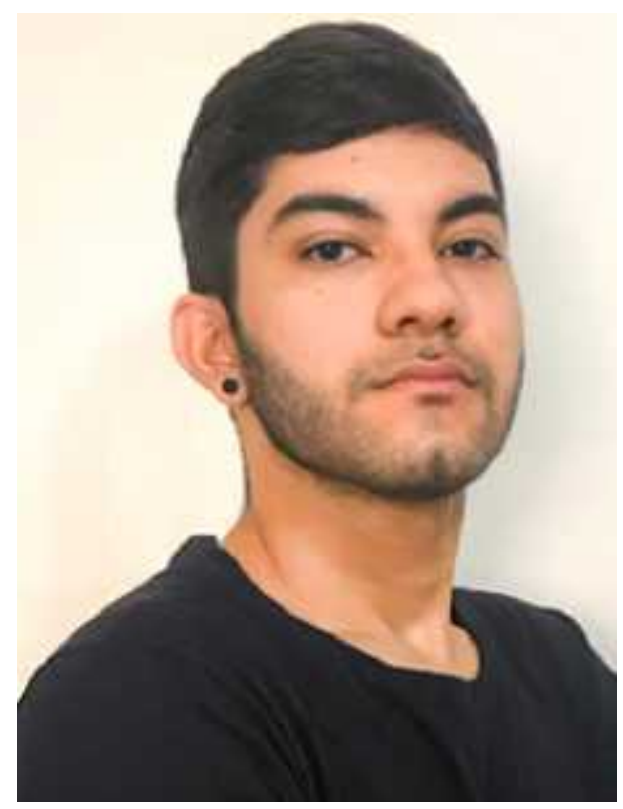

Graduando em Odontologia pelo Centro Universitário Católica de Quixadá

Membro do Grupo de Extensão em Odontologia Preventiva e Restauradora do Centro Universitário Católica de Quixadá

\section{Carlos lury Sant'Ana Furtado}

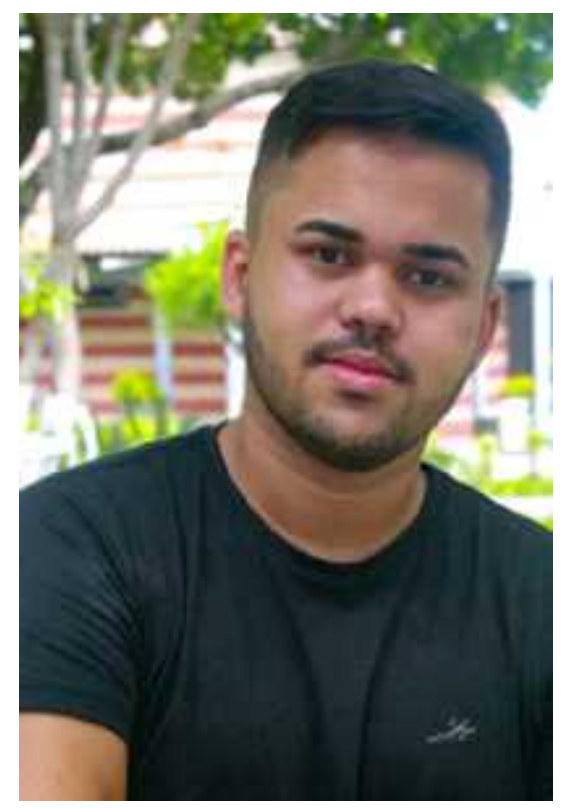

Graduando em Odontologia pelo Centro Universitário Católica de Quixadá;

Membro do Grupo de Extensão em Odontologia Preventiva e Restauradora do Centro Universitário Católica de Quixadá. 


\section{Sobre os Autores}

\section{Gabriela Soares Santana}

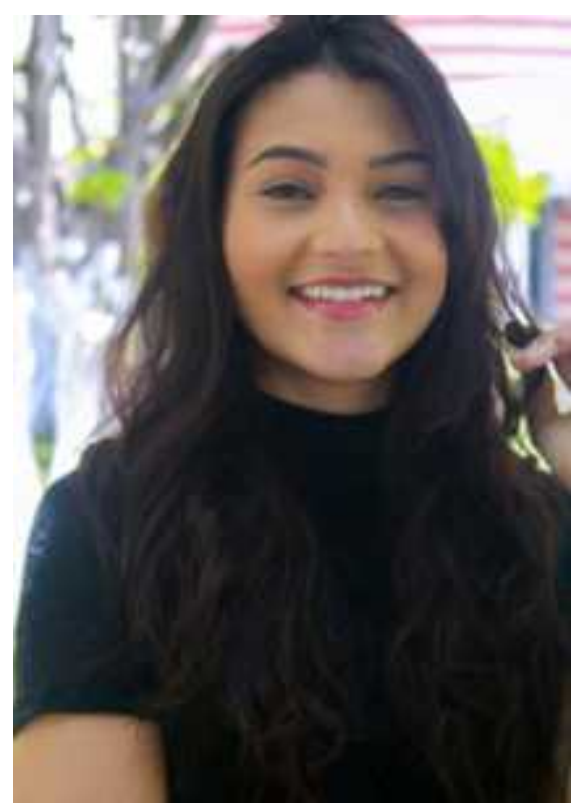

Graduanda em Odontologia pelo Centro Universitário Católica de Quixadá;

Membro do Grupo de Extensão em Odontologia Preventiva e Restauradora do Centro Universitário Católica de Quixadá. 


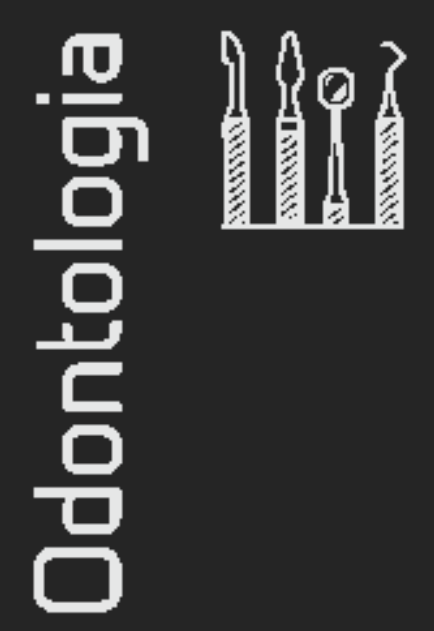

https://www.facebook.com/Synapse-Editora-111777697257115

(O) https://www.instagram.com/synapseeditora

in https://www.linkedin.com/in/synapse-editora-compartilhando-conhecimento/

(P) $3198264-1586$

editorasynapse@gmail.com
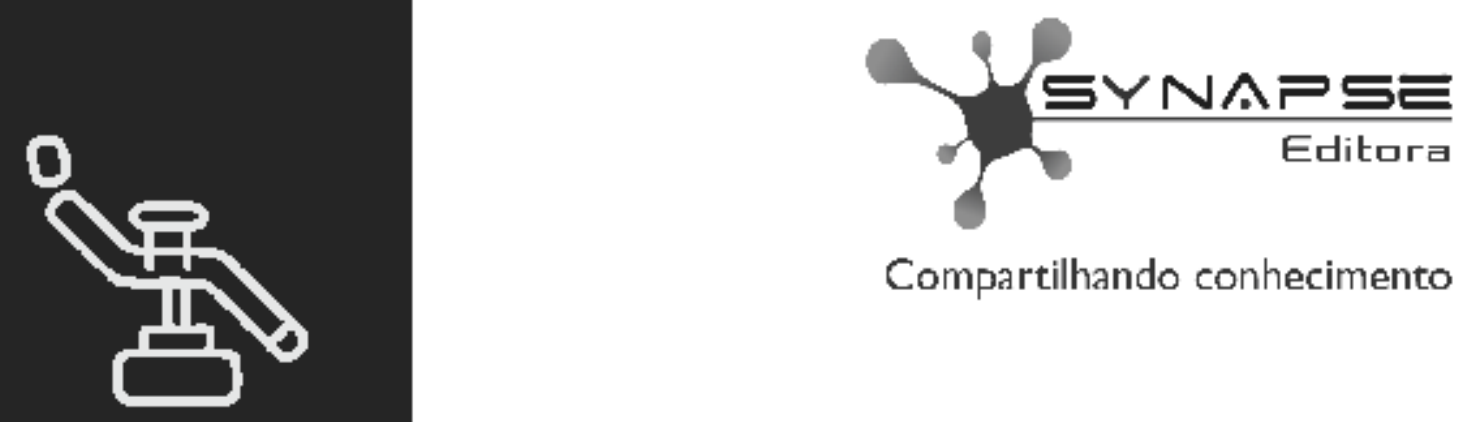

Compartilhando conhecimento 